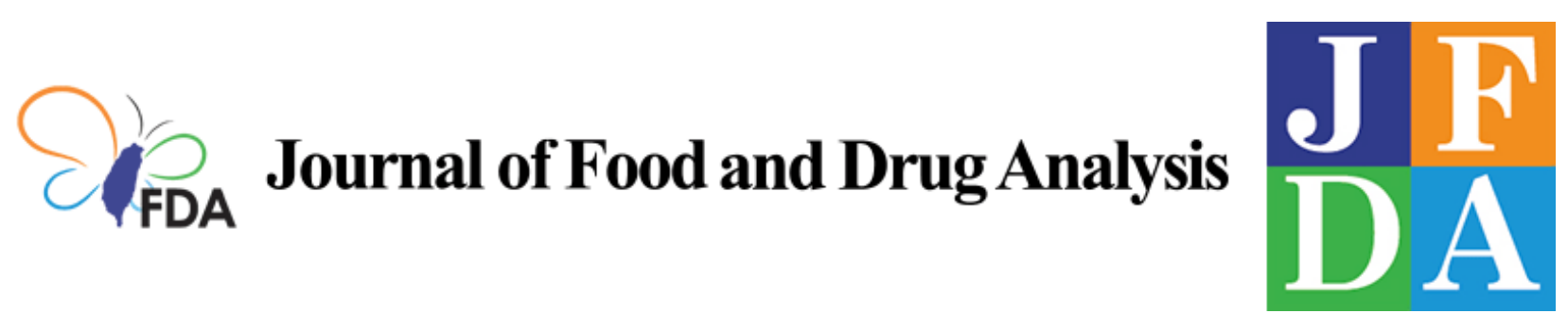

Volume 29 | Issue 1

Article 5

2021

\title{
Effects of Beer Based Marinades on the Plasmalogen Content and Composition of Grilled Ruminant Meats
}

Follow this and additional works at: https://www.jfda-online.com/journal

Part of the Food Science Commons, Human and Clinical Nutrition Commons, and the International and Community Nutrition Commons

(c) (i) $९ \bigcirc$

This work is licensed under a Creative Commons Attribution-Noncommercial-No Derivative Works 4.0 License.

\section{Recommended Citation}

Manful, Charles F.; Pham, Thu H.; Vidal, Natalia P.; Nadeem, Muhammad; Wheeler, Evan; Adigun, Oludoyin A.; Ayinla, Oluwashina A.; Keough, Dwayne N.; and Thomas, Raymond H. (2021) "Effects of Beer Based Marinades on the Plasmalogen Content and Composition of Grilled Ruminant Meats," Journal of Food and Drug Analysis: Vol. 29 : Iss. 1 , Article 5.

Available at: https://doi.org/10.38212/2224-6614.1193

This Original Article is brought to you for free and open access by Journal of Food and Drug Analysis. It has been accepted for inclusion in Journal of Food and Drug Analysis by an authorized editor of Journal of Food and Drug Analysis. 
Effects of Beer Based Marinades on the Plasmalogen Content and Composition of Grilled Ruminant Meats

\section{Cover Page Footnote}

We acknowledge the funding provided by Memorial University of Newfoundland. We thank Dr. Yuan Tao for maintaining instruments used in our analysis. 


\title{
Effects of beer based marinades on the plasmalogen content and composition of grilled ruminant meats
}

\author{
Charles Felix Manful a,*, Thu Huong Pham ${ }^{\text {a }}$, Natalia Prieto Vidal ${ }^{\text {a }}$, \\ Muhammad Nadeem a, Evan Wheeler a , Oludoyin Adesun Adigun a, Oluwashina Ayinla a, \\ Dwayne Keough ${ }^{b}$, Raymond Horatio Thomas ${ }^{a, *}$ \\ a School of Science and the Environment/Boreal Ecosystem Research Initiative, Grenfell Campus, Memorial University of Newfoundland,
Corner Brook, NL A2H 5G4, Canada
b Algoma University, 1520 Queen St E, Sault Ste. Marie, ON P6A 2G4, Canada
}

\begin{abstract}
Plasmalogens are important phospholipids essential for maintaining cardiovascular and brain health. Ruminant meats are excellent dietary sources of plasmalogens. Globally, grilling remains a popular technique for preparing meats. However, little is known concerning how marination affects retention and quality of plasmalogens in grilled ruminant meats. Here we present information on effects of two unfiltered beer-based marinades infused with herbs and spices on plasmalogens in grilled beef and moose meats. Although total plasmalogen contents of marinated grilled meats were lower compared to unmarinated controls; compositionally, wheat ale- and India session ale-based marinades retained higher levels of PUFA plasmalogen PC (phosphatidylcholine) and PE (phosphatidylethanolamine) species enriched with $\omega 3$ and $\omega 6$ fatty acids in grilled moose meats. In grilled beef, significantly higher levels of plasmalogen PC species enriched with monounsaturated fatty acids (MUFA) and PUFA were retained by Wheat ale-based marinade. Furthermore, strong positive correlations were observed between antioxidants, polyphenols, oxygenated terpenes and plasmalogens retained in the marinated grilled meats which contrasted negative correlations with total oxidation status of the marinated grilled meats. These findings appear to suggest that the phenolics, oxygenated terpenes and antioxidants present in the beer-based marinades preserved these plasmalogens in marinated meats against degradation during grilling. In view of the benefits associated with plasmalogens and essential fatty acid consumption, marination of beef and moose meats with unfiltered beer-based marinades could be useful for retaining MUFA and PUFA-enriched plasmalogens, as well as preserving the nutritional quality of grilled beef and moose meats.
\end{abstract}

Keywords: Antioxidants, Glycerophospholipids, Oxidation, Oxygenated terpenes, Polyphenols

\section{Introduction}

$\mathrm{T}$ he role lipids play in human health and prevention of diseases has been well documented including anticarcinogenicity and activity against cardiovascular diseases [1]. Among lipids, plasmalogens have received widespread interest due to their benefits in improving brain health and their association with reduced risks in neurodegenerative disorders [2]. As membrane glycerophospholipids (GPLs), plasmalogens are characterized by vinyl-ether linkage at $S n 1$, ester bond at $S n 2$ and polar head group at $S n 3$ positions of their glycerol backbone [3]. The head group is typically choline (plasmalogen phosphatidylcholine) or ethanolamine (plasmalogen phosphatidylethanolamine) and rarely, inositol (plasmalogen phosphatidylinositol), serine (plasmalogen phosphatidylserine) and threonine (plasmalogen phosphatidylthreonine). At Sn2 position, plasmalogens are typically enriched in PUFAs such as docosahexaenoic acid ( $\omega 3$ C22:6)

* Corresponding author: School of Science and the Environment/ Boreal Ecosystem Research Initiative, Grenfell Campus, Memorial University of Newfoundland, Corner Brook, NL A2H 5G4, Canada.

E-mail addresses: cfmanful@mun.ca (C.F. Manful), rthomas@grenfell.mun.ca (R.H. Thomas). 
and arachidonic acid ( $\omega 6$ C20:4) which cannot be biosynthesized by humans and must be acquired from diets and/or supplements.

Plasmalogens constitute $10-20 \%$ of total phospholipids in human cell membranes. In human brain, plasmalogens make up $55 \%$ of phospholipids and are involved in brain development and health [3]. Several studies have associated reduced plasmalogen contents with pathological conditions such as infant bronchopulmonary dysplasia, Alzheimer's disease, Parkinson's disease, Neimann-Pick disease type C, and Down syndrome [2]. In all these cases, increased lipid oxidation is known to accompany these pathological states and has been associated with decreased plasmalogen levels. Dietarily, meat constitutes a rich natural source of plasmalogens, and beef, lamb, deer, moose, caribou, mussel, and clam are excellent sources [4]. However, due to vinyl-ether linkage and enrichment in PUFAs plasmalogens are susceptible to oxidation during cooking [5].

During lipid oxidation, unsaturated fatty acids in meat react with oxygen or free radicals to form lipid hydroperoxides and secondary oxidation products, such as aldehydes responsible for development of rancidity, off-flavors, discoloration and quality loss [6]. The use of antioxidants to suppress lipid oxidation and preserve meat quality and sensory attributes is widely known, and the literature is replete with applications of antioxidant-rich spices, herbs, and beers to suppress oxidation of meat lipids during cooking [7, 8]. It is accepted that the antioxidant activity of herbs, spices and beers is due mainly to the presence of phenolic compounds and oxygenated terpenes, which are capable of donating hydrogen radicals and electrons for pairing with lipid radicals formed during lipid oxidation $[6,9$, 10]. To the best of our knowledge, there is a paucity of information in the scientific literature pertaining to the use of natural antioxidants to suppress deterioration of ruminant meat plasmalogens during cooking. Thus, the aim of this work is to investigate effects of unfiltered beer-based marinades enriched with herbs and spices on plasmalogens content and composition in two grilled ruminant meat systems.

This study is the first to examine the cumulative effect of dietary antioxidants obtained from unfiltered beer-based marinades on deterioration of beef and moose meat plasmalogens. Furthermore, we attempted to show the potential application of beerbased marinades in suppressing oxidative deterioration of plasmalogens and preserve ruminant meat quality during grilling.

\section{Materials and methods}

\subsection{Standards and reagents}

PC and PE lipid standard mix were purchased from Avanti Polar Lipids (Alabama, USA), and were used to generate standard calibration curves for quantification of PC and PE in grilled meats. All other reagents were purchased from Sigma Aldrich (Ontario, Canada) and were of analytical grade. All solvents used were of HPLC grade from VWR International (Ontario, Canada).

\subsection{Sample preparation}

\subsubsection{Preparation of marinades}

Two types of unfiltered beers were used in this study: India session ale (M) and White ale (S). Both beers were purchased from a local market in Corner Brook, Newfoundland and Labrador Canada, and are designated by the manufacturers as unfiltered beers. India session ale contained $4.3 \%$ alcohol and was made from water, malted barley, and hops; Wheat ale contained $5.2 \%$ alcohol, and was made from water, malted wheat, barley, orange, lemon, lime peel, coriander, Cascade and Willamette hops. To $341 \mathrm{~mL}$ of each type of unfiltered beer $(81.2 \%), 1$ $\mathrm{g}$ oregano $(0.2 \%), 1 \mathrm{~g}$ of parsley $(0.2 \%), 4 \mathrm{~g}$ of mustard $(0.9 \%), 2 \mathrm{~g}$ of salt $(0.5 \%), 8 \mathrm{~g}$ of pepper $(1.9 \%), 1 \mathrm{~g}$ of garlic $(0.2 \%), 25 \mathrm{~mL}$ of olive oil $(5.4 \%)$, $15 \mathrm{~mL}$ of vinegar $(3.5 \%)$ and $25 \mathrm{~g}$ of fresh onions $(5.9 \%)$ purchased from a local market were added to a food processor (Kenwood Chef Titanium, model KMC010) and the contents homogenized and mixed thoroughly (speed $=1$, room temperature, $5 \mathrm{~min}$ ) to obtain $424.3 \mathrm{~g}$ of beer-based marinades that was further employed to marinate the moose and beef meat samples [6, 11].

\subsubsection{Marination of ruminant meat samples}

Beef (Bovinae) and moose (Cervidae) striploin steaks (Longissimus thoracis et lumborum) were obtained from a local market and from Newfoundland and Labrador Department of Natural Resources, respectively. Moose steaks were taken from 4 different animals while 4 different beef steak batches were used to mitigate any inherent variability of the meat source. Ethics approval [file number 20160041] for this study was granted by Memorial University Animal Care Committee as mandated by the Canadian Council on Animal Care and all the experiments were performed in accordance with relevant guidelines and regulations. Steaks (1 lb) of beef (B) and moose (M) meat from different batches were cut and divided into four 
replicates $(\mathrm{n}=4)$ per treatment $(\mathrm{n}=3)$. Each replicate was made from an independent batch of beer and ingredients. The steaks were divided into three groups as follow: control group (unmarinated, $\mathrm{U})$, treatment group marinated with India session ale-based marinade (M) and treatment group marinated with White ale beer-based marinade (S). Meat marination was performed by adding $600 \mathrm{~mL}$ of each beer-based marinade to the beef and moose steaks for $12 \mathrm{~h}$ at $4{ }^{\circ} \mathrm{C}$ in zip lock closed plastic bags. The unmarinated samples (U, control) were kept under the same conditions as the marinated ones until grilling time $[6,11]$.

\subsubsection{Cooking conditions}

Beef and moose unmarinated (BU, MU) and marinated (BM, BS; MM, MS) samples were grilled at $200-250{ }^{\circ} \mathrm{C}$ for $25 \mathrm{~min}$ on a grill (Cuisinart ${ }^{\circledR}$ ) Gourmet 600B) reaching an internal temperature of $75{ }^{\circ} \mathrm{C}$. A probe thermometer (Accu-Temp Instant Read Thermometer, model 65613) was used to measure the internal temperature of the meat during grilling. In both types of meat, the unmarinated meat was cooked before the marinated ones. The barbeque was thoroughly cleaned between samples to avoid any possible contamination of marinade flavors. Meat samples were turned every 2-3 $\mathrm{min}$ during grilling to ensure uniform internal temperature of $75{ }^{\circ} \mathrm{C}$ of cooked meats. After grilling, each replicate was divided into two subsets. One subset was cut into two-inch cubes and used for sensory analysis, while the other subset was labeled and stored at $-80{ }^{\circ} \mathrm{C}$ to protect meat lipids and antioxidants against degradation prior to chemical analysis.

\subsection{Extraction and analysis of antioxidants, polyphenols and pro-oxidants}

Detailed procedures for extraction and colorimetric analysis of antioxidants, polyphenols and pro-oxidants are provided in our previous publications $[6,11]$. Briefly, total polyphenol and antioxidant analyses were based on the Folin-Ciocalteu (FC) and ABTS antioxidant methods respectively $[12,13]$ while oxidation status was assessed by the method of Erel, 2005 [14]. Results from ABTS method were corroborated by measuring total antioxidant content using Ferric reducing antioxidant power (FRAP) method [15]. Four experimental replicates of meat treatments were used for colorimetric analyses $(\mathrm{n}=4)$. Detailed results and discussion of colorimetric analysis of antioxidants, polyphenols and pro-oxidants are described in detailed in our previous publication [11].

\subsection{Extraction of meat lipids}

Lipids were extracted from ground grilled meat (1 g) according to Folch method using $2 \mathrm{~mL}$ chloroform/methanol $(2: 1, \mathrm{v} / \mathrm{v})$ [16]. The mixtures were homogenized, incubated $\left(0{ }^{\circ} \mathrm{C}, 10 \mathrm{~min}\right)$, and centrifuged $\left(0{ }^{\circ} \mathrm{C}, 10000 \mathrm{rpm}, 10 \mathrm{~min}\right)$. The organic phases were pooled and evaporated under nitrogen at room temperature to obtain dried lipids [17]. The dried lipids were reconstituted in $100 \mu \mathrm{L}$ chloroform for LC-MS analysis.

\subsection{Lipid analysis by ultra-high performance \\ liquid chromatography/high resolution accurate mass tandem mass spectrometry (UHPLC/ HRAMS/MS)}

The lipids and standards were resolved on a Accucore C30 column $(150 \times 2 \mathrm{~mm}$ I.D., particle size: $2.6 \mu \mathrm{m}$, pore diameter: $150 \AA$; Thermo Fisher Scientific, ON, Canada) coupled to a Dionex Ultimate 3000 ultra-high performance liquid chromatography system and Q-Exactive mass spectrometer (Thermo Fisher Scientific, ON, Canada). The mobile phase consisted of Solvent A (acetonitrile:water, 60:40 v/v) and solvent B (isopropanol:acetonitrile:water, 90:10:1 v/v/v) with both solvents containing $10 \mathrm{mM}$ ammonium formate and $0.1 \%$ formic acid. The gradient for separation was as follows: $30 \% \mathrm{~B}$ for $3 \mathrm{~min}$; $43 \%$ B for $5 \mathrm{~min}, 50 \%$ B for $1 \mathrm{~min}, 90 \%$ B for $9 \mathrm{~min}, 99 \%$ B for $8 \mathrm{~min}, 99 \%$ B for $4 \mathrm{~min}$ and reequilibrated at $70 \%$ A for $5 \mathrm{~min}$. The column temperature was $30{ }^{\circ} \mathrm{C}$ with a flow rate of $0.2 \mathrm{~mL} / \mathrm{min}$. The mass spectrometer was operated in both positive and negative modes with sheath gas: 40 , auxiliary gas: 2, ion spray voltage: $3.5 \mathrm{kV}$, capillary temperature: $300{ }^{\circ} \mathrm{C}$; S-lens RF: $35 \mathrm{~V}$; mass range: $200-2000 \mathrm{~m} / \mathrm{z}$; full scan mode at a resolution of $70,000 \mathrm{~m} / \mathrm{z}$; top-20 data dependent MS/MS at a resolution of $35,000 \mathrm{~m} / \mathrm{z}$ and step collision energy of 35 and 40 (arbitrary unit); injection time: $50 \mathrm{~min}$; isolation window: $1 \mathrm{~m} / \mathrm{z}$; automatic gain control target: 1e5, and dynamic exclusion: 5.0s. Lipid concentrations were expressed on $\mathrm{mg} / \mathrm{g}$ meat and $\mathrm{nmol}$ $\%$ basis. The difference between lipid subclass and plasmalogen molecular species levels in marinated and unmarinated grilled meat samples was calculated using the equation: 


$$
\% \text { retention } / \text { loss }=\left(\frac{\text { marinated }- \text { unmarinated }}{\text { unmarinated }}\right) * 100
$$

\subsection{Data processing}

Xcalibur 4.0 (Thermo Scientific, MO, USA) and LipidSearch 4.1 (Mitsui Knowledge Industry, Tokyo, Japan) were used for data processing. LipidSearch parameters were as follows: target database: $Q$ Exactive; precursor tolerance: $5 \mathrm{ppm}$; product tolerance: $5 \mathrm{ppm}$; product ion threshold: $5 \%$; mscore threshold: 2; Quan $\mathrm{m} / \mathrm{z}$ tolerance: $\pm 5 \mathrm{ppm}$; Quan RT (retention time) range: $\pm 1 \mathrm{~min}$; use of all isomer filter and ID quality filters $\mathrm{A}, \mathrm{B}$, and $\mathrm{C}$; Adduct ions: $+\mathrm{NH}_{4}$ for positive ion mode, and $-\mathrm{H}$, for negative ion mode. The alignment parameters were first optimized using lipid standards before being applied to targeted lipidomics analysis. Positions of the fatty acyls (fatty acids) present in the molecular species were identified based on fragmentation patterns of MS/MS spectra in the LipidSearch database, and manually confirmed using Xcalibur 4.0 according to well-recognized rules established by tandem mass spectrometry [18]. The LipidSearch output including the peak areas and exact masses of molecular species were used to calculate the relative concentrations $(\mathrm{nmol} \%)$ of lipid molecular species in the grilled meats samples. Furthermore, the absolute concentrations $(\mathrm{mg} / \mathrm{g})$ of lipid molecular species were calculated based on the peak areas of molecular species using standards curves generated from plasmalogen PC and PE standards.

\subsection{Statistical analysis}

Analysis of variance (ANOVA) was used to determine if there were significant differences between glycerophospholipid classes, subclasses and plasmalogen contents in marinated and unmarinated grilled moose and beef samples. Where treatment effects were significant, means were compared with Fisher's Least Significant Difference (LSD), $\alpha=0.05$. Principal component analysis (PCA) was performed on concentrations (nmol \%) of plasmalogen PC and PE molecular species of unmarinated and marinated grilled meat samples. To determine linear correlations between plasmalogen molecular species and antioxidants and phenolics, Pearson's correlation coefficients were used. Statistical analysis was performed using XLSTAT (Addinsoft, Boston, USA).

\section{Results and discussion}

The major classes of GPLs detected in grilled beef and moose meats by UHPLC/HRAMS/MS included phosphatidylcholines (PC), phosphatidylethanolamines (PE), lysophosphatidylcholines (LPC), and lysophosphatidylethanolamines (LPE) as shown in Fig. 1 and $2 a-b$. In accordance with previous findings PC, PE, LPC and LPE plasmalogens (pPC, pPE, pLPC, and pLPE respectively) were also detected [19]. Fig. 1 shows chromatograms and mass spectra of representative plasmalogens detected in grilled meat samples. The total plasmalogen composition content was calculated from sum of concentrations of plasmalogen species present in the grilled meat samples and expressed on nanomole percent (nmol $\%$ ) and $\mathrm{mg} / \mathrm{g}$ basis.

\subsection{Total GPL distribution in grilled beef and moose meats}

The objective of this study was to evaluate effects of unfiltered beer-based marination on plasmalogen PC and PE lipids in grilled moose and beef. Total crude lipid yields obtained under standard Folch extraction conditions were $3.92 \pm 0.56 \mathrm{~g} / 100 \mathrm{FW}$ and $0.68 \pm 0.08 \mathrm{~g} / 100 \mathrm{FW}$ for grilled beef and moose samples respectively [20]. Fig. $2 a-f$ shows distribution of major GPLs extracted from unmarinated and marinated grilled beef and moose samples with PE and $\mathrm{PC}$ together constituting the major proportion $(>90 \%)$ of GPLs in the grilled meat samples in relation to their lyso counterparts [21, 22]. Furthermore, grilled beef was significantly enriched in PC whereas grilled moose was richer in PE lipids (Fig. $2 \mathrm{a}$ and $\mathrm{b}$ ). Compared with beef, no data is available in the literature on phospholipid content of cooked or raw moose meat and to the best of our knowledge very little data exist on phospholipid distributions in cervid meats in general [23, 24]. Significantly, GPL composition in grilled moose meat was consistent with other ruminant and non-ruminant meats [21, 22]. It must be pointed out that the levels of GPLs in grilled moose was higher compared to grilled beef samples, in line with previous studies that showed higher GPL content of ungulate cervids such as elk, antelope and deer compared to range and feedlot cattle [23-25]. This is best exemplified in the total PC content of MU (10.01 $\pm 0.11 \mathrm{mg} / \mathrm{g}$ meat) and BU (3.65 $\pm 0.01 \mathrm{mg} / \mathrm{g}$ meat) shown in Fig. $2 \mathrm{c}$ and e. This variance in total GPL content between the grilled beef and moose meats could be due to the lower intramuscular fat content in moose meat compared to beef, and could be the result of factors including 
(a) NLS 60
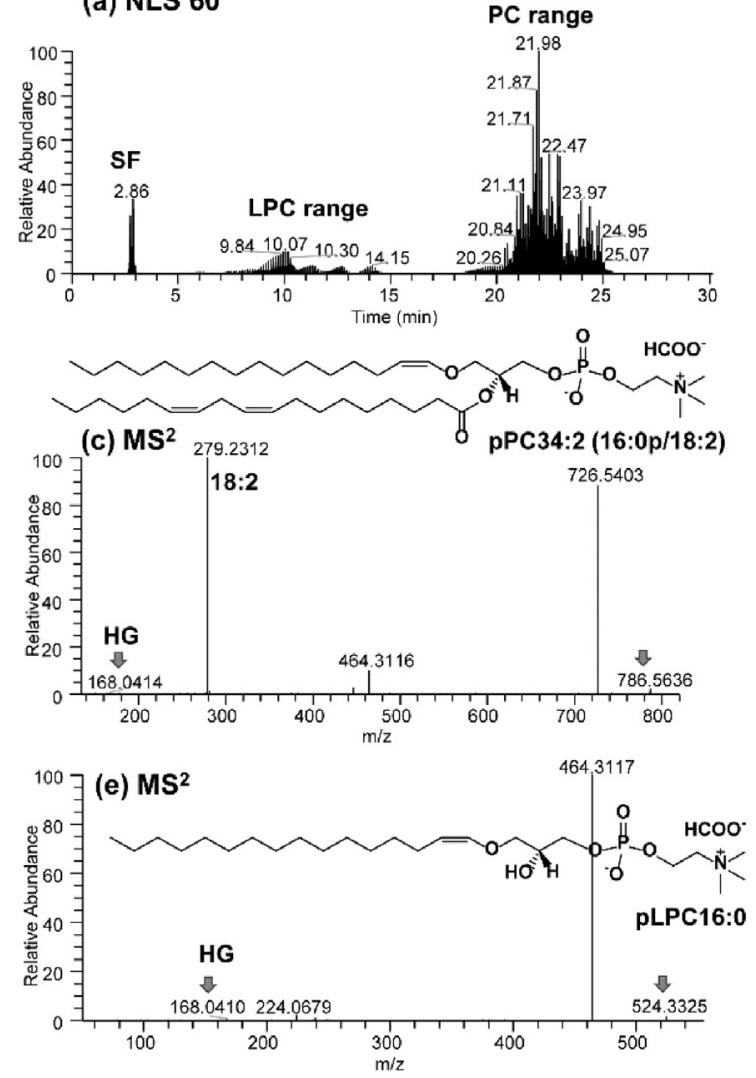

(b) PIS $m / z 140$
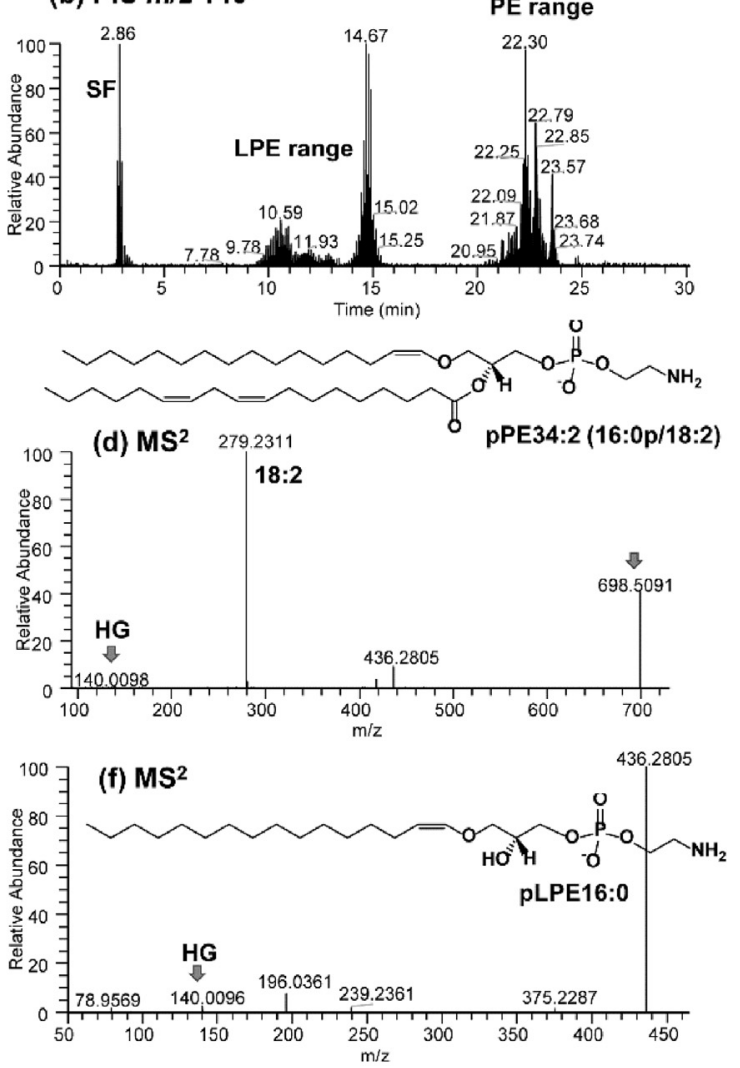

Fig. 1. Total ion chromatograms and HILIC-HRAM-MS spectra of plasmalogens species in unmarinated grilled moose meats showing. a) neutral loss spectrum (NLS) of 60 Da representing choline head group b) product ion spectrum (PIS) of 140 Da representing ethanolamine head group c) mass spectrum of pPC 34:2 (16:0p/18:2) d) mass spectrum of pPE 34:2 (16:0p/18:2) e) mass spectrum of pLPC 16:0 g) mass spectrum of pLPE 16:0. $p=$ plasmalogen, $L=$ lyso, $P C=$ phosphatidylcholine, $P E=$ phosphatidylethanolamine, $p L P E=$ plasmalogen-lyso-phosphatidylethanolamine, $p L P C=$ plasmalogen-lyso-phosphatidylcholine, $H G=$ head group, $S F=$ solvent front.

phylogenetic origin, feeding regime/diet, and age [23-25].

The total PC and PE contents in marinated grilled meat samples were significantly $(P<0.05)$ lower compared to unmarinated controls, suggesting losses due possibly to oxidative and/or hydrolytic degradative processes during grilling (Fig. 2c-f). Significantly, these losses were not commensurate with increases in lyso PC and PE in marinated grilled meats which could indicate complete oxidation/hydrolysis of PC, PE and lyso lipids (LPC and LPE) to free fatty acids and phosphatidic acids during [26]. In addition, LPE was higher than LPC in unmarinated grilled beef and moose samples (Fig. $2 \mathrm{c}$ and e) in line with possibly the greater lability of PE species to degrade to LPE compared to PC species [21].

In summary, beef and moose meat constitute rich natural sources of dietary PE, PC and lyso GPLs essential for cell membrane formation, permeability, structural integrity and functions. In view of the importance of GPLs to health, ruminant meats especially grilled moose meat could provide a natural source of GPLs in the diet.

\subsection{Plasmalogen PC and PE distribution in grilled moose and beef meats}

Fig. $3 a-g$ and $4 a-g$ show the composition of PE and PC in grilled moose and beef samples respectively, which consisted mainly of diacyl, ether, and plasmalogen subclasses [27]. Diacyl PC constituted the largest proportion of $\mathrm{PC}$ in the grilled meats ( $45 \%$ and $62 \%$ in MU and BU respectively), followed by plasmalogen PC (pPC) > ether PC (ePC) subclasses in marinated and unmarinated grilled meat samples (Fig. $3 a-c$ and $4 a-c$ ). By contrast, PE was more enriched in plasmalogens (pPE) compared to PC, and PE subclasses ranged as follows: plasmalogen $(\mathrm{pPE})>$ diacyl $(\mathrm{dPE})>$ ether $(\mathrm{ePE})$ in grilled 


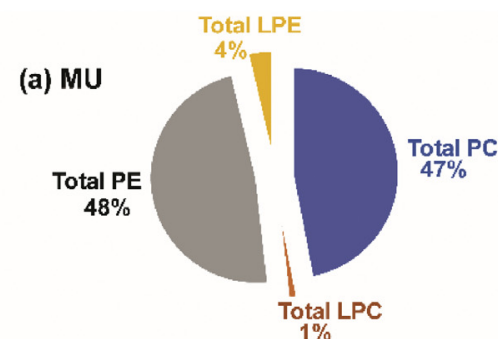

(c)

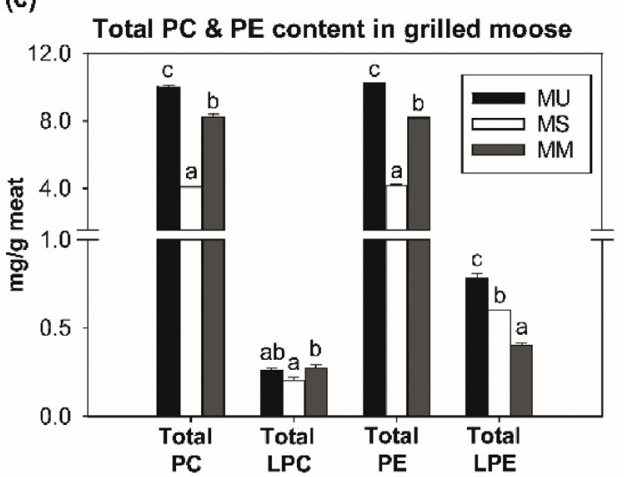

(e)

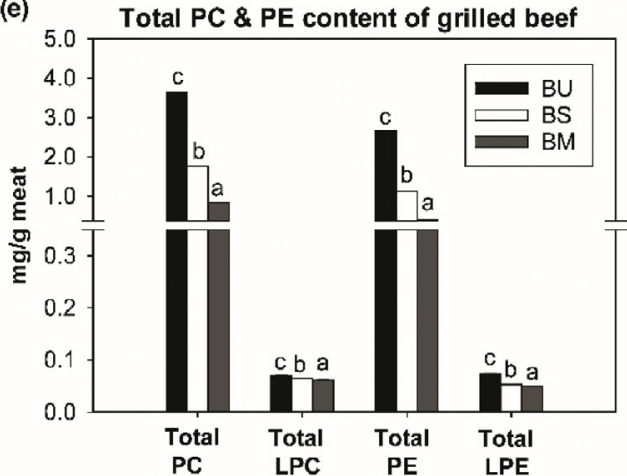

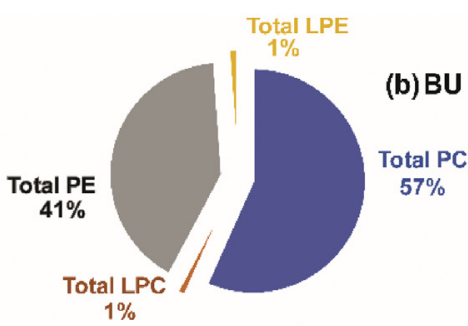

(d) Total PC \& PE content changes in moose

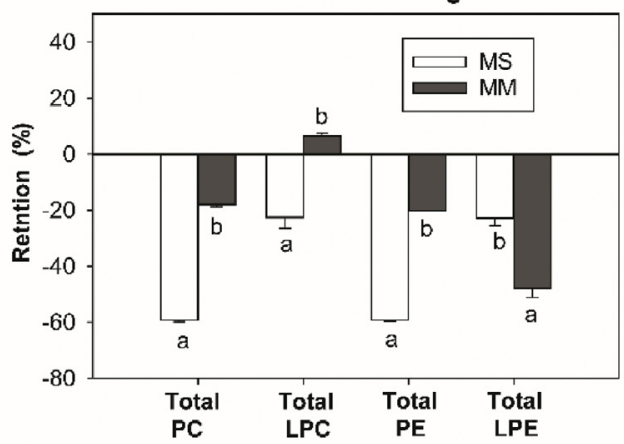

(f)

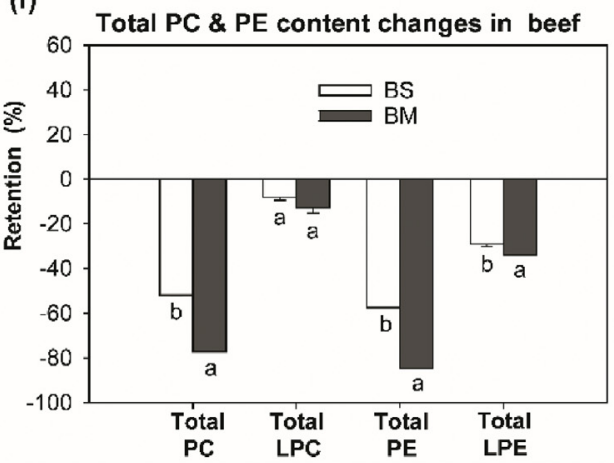

Fig. 2. Total phospholipids classes in grilled meats. Values in bar charts represent means \pm standard errors. Means accompanied by different letters are significantly different at $L S D(P<0.05 ; n=3)$. Total phospholipids composition (\%) in a) unmarinated grilled moose b) unmarinated grilled beef. Total phospholipids content $(\mathrm{mg} / \mathrm{g})$ in c) grilled moose samples e) grilled beef samples. Total phospholipid content changes (\%) in d) grilled moose samples $f)$ grilled beef samples. Total PC $=$ diacyl PC + ether PC + plasmalogen $P C+$ Total LPC. Total PE $=$ diacyl PE + ether PE + plasmalogen $P E+$ Total LPE. Total LPC = acyl LPC + ether LPC + plasmalogen LPC. Total LPE = acyl LPE + ether LPE + plasmalogen LPE. [BU, MU] $=$ unmarinated grilled beef and moose; $[B M, M M]=$ Indian Session Ale unfiltered beer-based marinated grilled beef and moose; $[B S, M S]=$ wheat Ale unfiltered beer-based marinated grilled beef and moose.

moose and beef respectively (Fig. $3 d-f$ and $4 d-f)$. In both grilled meats, lyso PC and PE (LPC and LPE) were generally in the least proportion (1-6\%) compared to their diacyl and ether counterparts except in grilled moose samples where LPE ranged from $20-21 \%$ (Fig. $3 a-f$ and $4 a-f$ ). Significantly, these trends are represented in the literature for ruminant and non ruminant cooked and raw meats including beef, pork, and duck [22, 28, 29]. Furthermore, the relative distribution of PE and PC subclasses $(\mathrm{nmol} \%)$ in grilled meat samples varied in response to beer-based marination as shown in Fig. $3 \mathrm{~g}-\mathrm{h}$ and $4 \mathrm{~g}-\mathrm{h}$. Focusing on plasmalogens, pPC levels were higher in BS but lower in BM samples when compared to the unmarinated control (Fig. $4 \mathrm{~g}$ ), and the differences corresponded to retention of pPC in BS samples resulting possibly from suppression of oxidative/hydrolytic degradative processes by antioxidants in Wheat ale-based marinade (S). The marinades used in this study are 

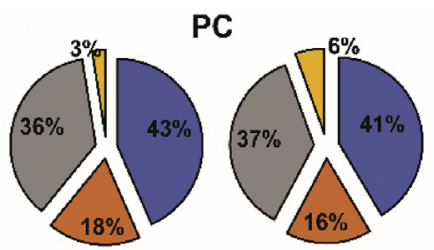

(a) MS

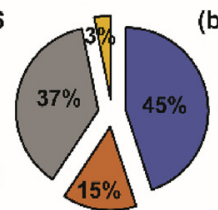

QPC (acyls) $\square$ ePC $\square$ pPC $\square$ LPC (total)

(g)

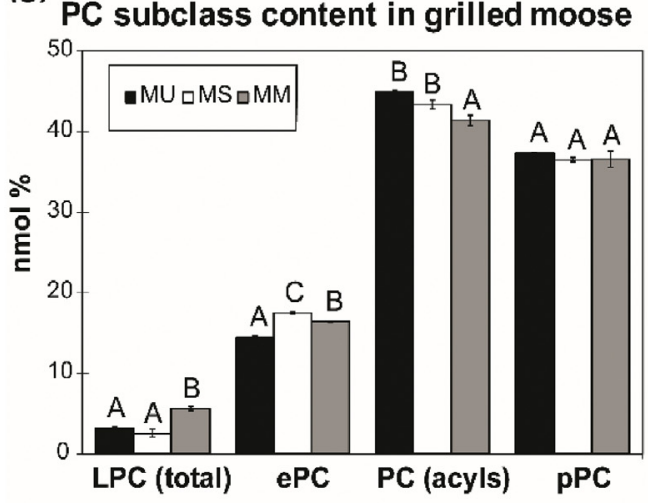

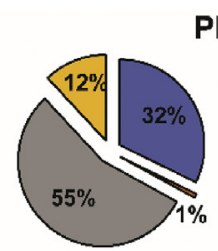

PE

(d) MS $21 \%$

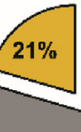

(f) MU

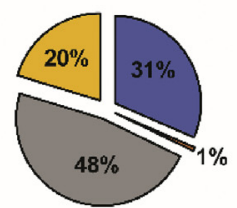

(e) MM

(h)

GPE (acyls) DePE Q PPE QLPE (total)

PE subclass content in grilled moose

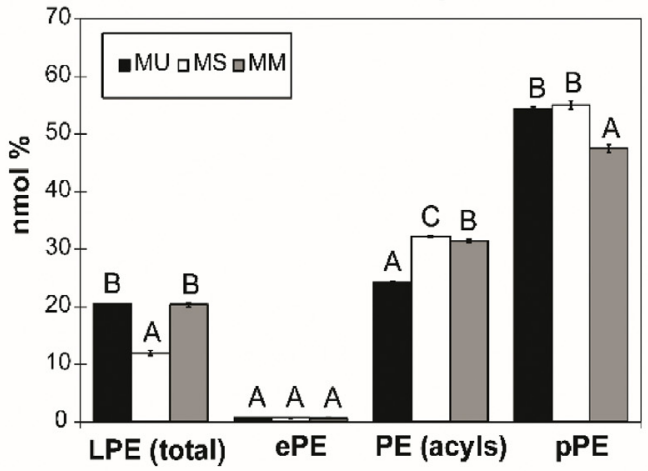

(i)

Plasmalogens content in grilled moose

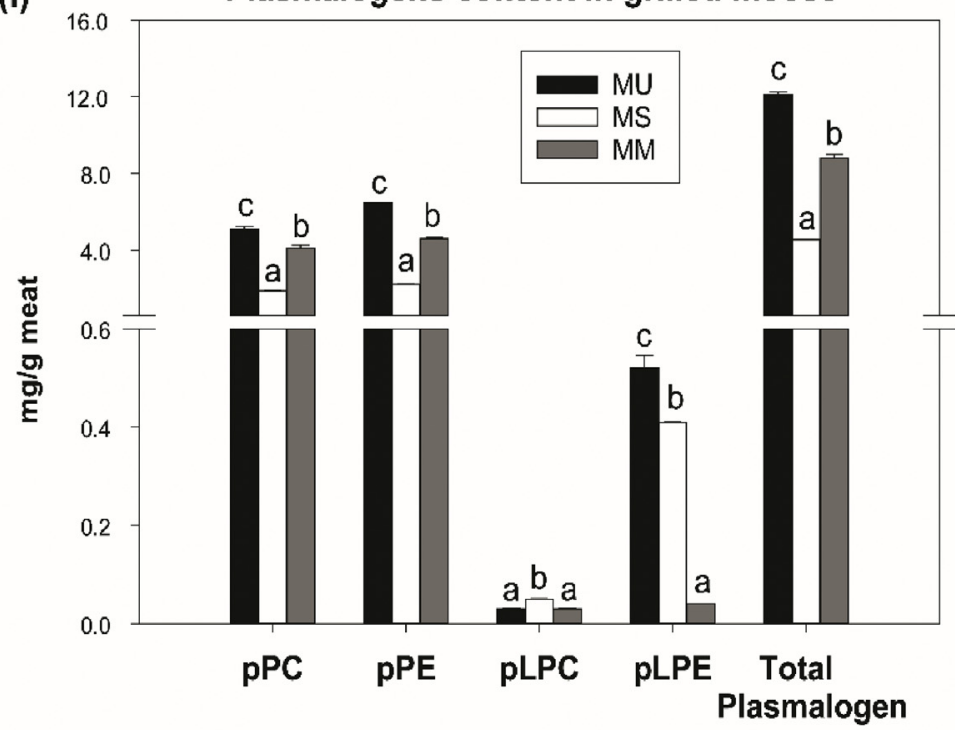

Fig. 3. Distribution of PC and PE subclasses in grilled moose meats. Values in bar charts represent mean \pm standard errors. Means accompanied by different letters are significantly different at LSD ( $<0.05 ; n=3)$. a-c) PC subclass composition (\%) in grilled $M U, M S$ and $M M$ samples respectively. $d-f) P E$ subclass composition (\%) in grilled $M U, M S$ and $M M$ samples respectively. $g$ ) PC subclass distribution (nmol\%) in grilled moose samples $\mathrm{h}$ ) PE subclass distribution (nmol\%) in grilled moose samples i) Plasmalogens content ( $\mathrm{mg} / \mathrm{g}$ meat) in grilled moose samples. [MU] = unmarinated grilled moose; $[M M]=$ India session ale -based marinated grilled moose; $[M S]=$ wheat ale based marinated grilled moose. $p=$ Plasmalogen $L=$ Lyso; $P E=$ Phosphatidylethanolamine; $P C=$ Phosphatidylcholine.

composed of herbs, spices olive oil, and unfiltered session beers rich with polyphenols and oxygenated terpene compounds possessing antioxidant properties which are known to suppress lipid oxidation in cooked and raw meats, and could have been involved in suppression of oxidative/hydraulic 


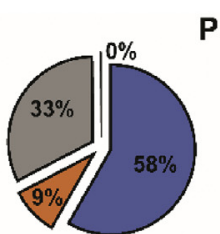

PC

(a) BS

(c) BU

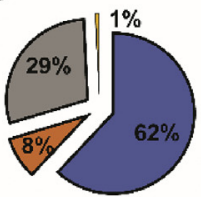

(b) BM

$\square$ PC (acyls) DePC口 PPC $\cong$ LPC (tot al)

(g) PC subclass content in grilled beef

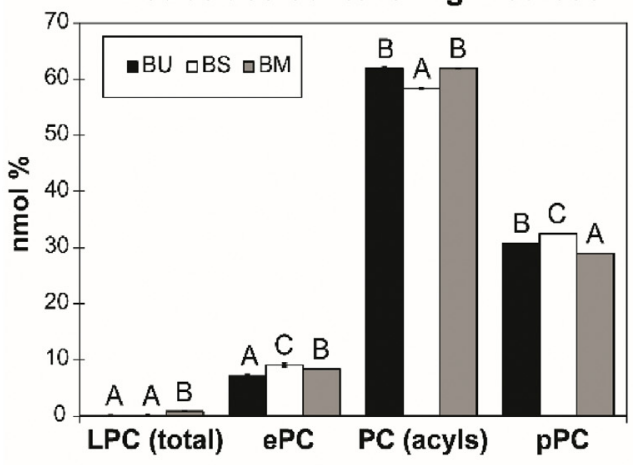

PE

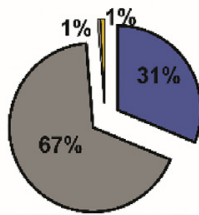

(d) BS

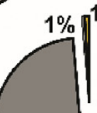

$1 \%$
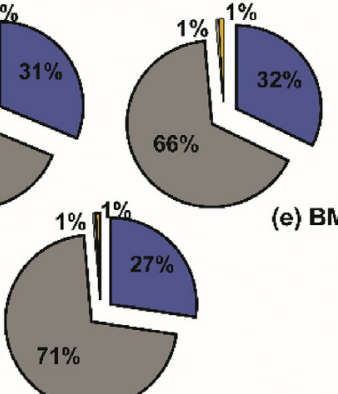

(e) BM

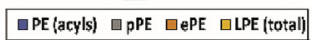

(h)

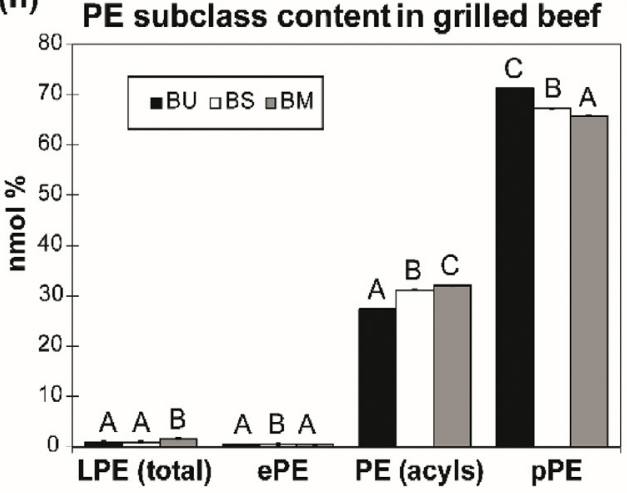

(i) Plasmalogens content in grilled beef

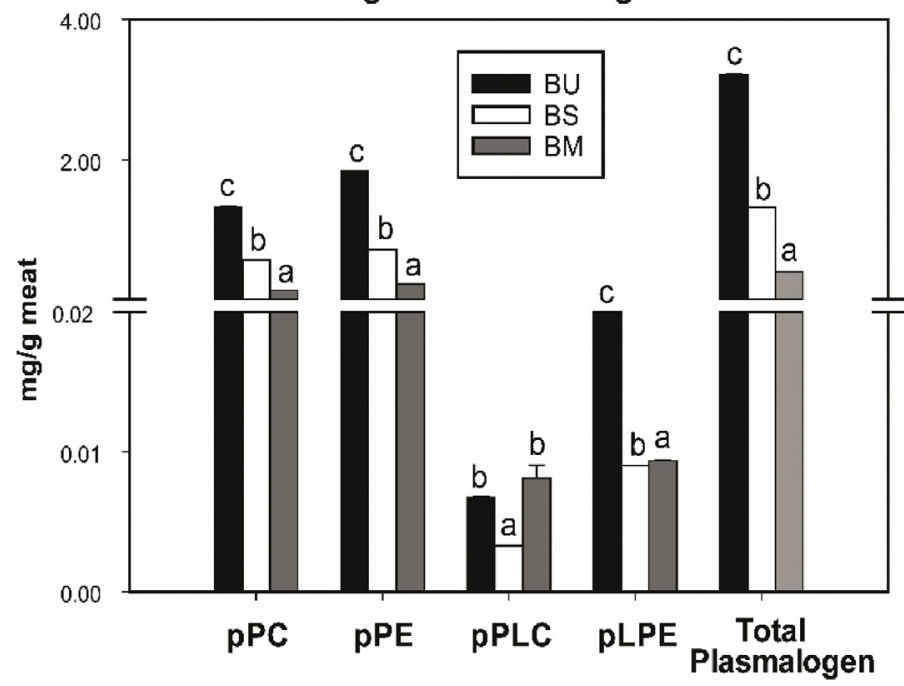

Fig. 4. Distribution of PC and PE subclasses in grilled beef meats. Values in bar charts represent mean \pm standard errors. Means accompanied by different letters are significantly different at $L S D(P<0.05 ; n=3)$. a-c) $P C$ subclass composition (\%) in grilled $B U, B S$ and $B M$ samples respectively. $d-f) P E$ subclass composition (\%) in grilled BU, BS and BM samples respectively. $g$ ) PC subclass distribution (nmol\%) in grilled beef samples $h$ ) PE subclass distribution (nmol\%) in grilled beef samples i) Plasmalogens content ( $\mathrm{mg} / \mathrm{g}$ meat) in grilled beef samples. [BU] $=$ unmarinated grilled beef; $[B M]=$ India session ale -based marinated grilled beef; $[\mathrm{BS}]=$ wheat ale based marinated grilled beef. $p=$ Plasmalogen; $L=$ Lyso; PE $=$ Phosphatidylethanolamine; $P C=$ Phosphatidylcholine.

degradative processes in BS [6, 30, 31]. However, the marinades used in current study contained the same kind and quantities of herbs and spices but differed in terms of type of unfiltered session ale used as bases in formulating the marinades. Wheat alebased marinade contained unfiltered Wheat ale 
beer whereas India session ale-based marinade contained India session ale with different phenolic and antioxidant profiles, which appears to suggest that the combination of the antioxidant rich herbs, spices, olive oil and Wheat ale beer exerted a greater inhibitory effect on oxidative/hydrolytic degradation of $\mathrm{pPC}$ in beef during grilling compared to India session ale-based marinade. In contrast, pPC levels in grilled moose were not significantly $(P<$ 0.05) different in MS, MM and MU samples (Fig. 3g). The difference between grilled beef and moose pPC response to marination could be due to variations in composition of intramuscular fat and their interactions with the antioxidants in the herbs, spices, olive oil and unfiltered beers in the marinades which could affect their oxidative stability during grilling [22]. Whilst no data exist in the literature on the pPC in moose meat, Fogerty et al, 1990 had reported similar greater loss of PUFA enriched PC lipids including plasmalogens in cooked beef compared to PUFA PC in cooked lamb, veal, chicken and pork [32].

ePC was significantly $(P<0.05)$ higher in marinated grilled beef and moose samples compared to unmarinated controls (Fig. $3 \mathrm{~g}$ and $4 \mathrm{~g}$ ) which could be due possibly to suppression of oxidative/hydrolytic degradative processes by antioxidants in the marinades. A similar trend was observed for LPC (total) which was significantly $(P<0.05)$ higher in India session ale-marinated grilled beef and moose samples compared to the controls (Fig. $3 \mathrm{~g}$ and $4 \mathrm{~g}$ ). These trends were in line with our previous work which showed reduction in the oxidation levels, and enhanced antioxidant and phenolic contents of beer-based marinated grilled beef and moose meats compared to their unmarinated counterparts $[6,11]$. $\mathrm{dPC}$ levels were generally lower in marinated grilled meats compared to the unmarinated controls (BU and MU) with significantly $(P<0.05)$ greater loss in $\mathrm{MM}$ and BS due possibly to degradative processes during grilling. Taken altogether, it appears that degradative loss of $\mathrm{dPC}$ (and not $\mathrm{pPC}$ or LPC) contributed most to the reduction of total PC content in marinated grilled beef and moose meats (Fig. 2c-d and Fig. 2e-f).

Compared to PC, PE subclasses are distinguished by ethanolamine head group at $S n 3$ position of their glycerol backbone. Plasmalogen PE (pPE) levels $(\mathrm{nmol} \%)$ were significantly $(P<0.05)$ lower in marinated grilled beef samples (BS and BM) and MM compared to unmarinated controls (BU and $\mathrm{MU})$ as shown in Fig. $4 \mathrm{~h}$ and $3 \mathrm{~h}$ respectively. These differences appear to suggest loss of pPE in MM, $\mathrm{BM}$ and BS samples due possibly to oxidative/hydrolytic degradative processes during grilling. In contrast to dPC, dPE levels (nmol\%) in grilled moose and beef were significantly $(P<0.05)$ higher in the marinated meats (MM, MS and BM, BS) compared to MU and BU respectively (Fig. $3 \mathrm{~h}$ and 4h) which could suggest suppression of degradative processes by the marinades used in view of the antiradical properties of the herbs, spices and beers used in marinades formulation $[6,10]$. No significant $(P<0.05)$ differences were observed in ePE levels (nmol\%) in grilled moose and beef samples except in BS, which was significantly higher compared to $B U$, and may suggest suppression of degradative processes during grilling of BS samples (Fig. 4h). The trend for LPE in grilled beef was similar to LPC whereas in grilled moose, LPE was significantly $(P<$ 0.05 ) lower in BS compared to BU samples possibly caused by oxidative degradative processes during grilling (Fig. 4h). In summary, the results for PE subclass distribution following marination and grilling suggest that degradation of $\mathrm{pPE}$ (and not $\mathrm{dPE})$ accounted more for the decrease in total PE content observed in grilled moose and beef (Fig. 2c $-d$ and e-f). Furthermore, the reduction in pPE levels in marinated grilled moose and beef were not commensurate with increases in LPE, and suggest as alluded previously to the possibility that most of LPE was completely hydrolyzed further to free fatty acids and phosphatidic acids during grilling (Fig. $3 a-f$ and $4 a-f)$.

The total plasmalogen content ( $\mathrm{mg} / \mathrm{g}$ meat) was significantly lower in marinated grilled moose and beef compared to the controls (Fig. $3 \mathrm{i}$ and $4 \mathrm{i}$ ). This could possibly be the result of thermal/oxidative/ hydrolytic degradation of plasmalogens during grilling of marinated meat samples [32]. These results however suggest that some subclasses of plasmalogens were preserved by beer-based marination even though a reduction in total plasmalogen contents was observed in the grilled marinated meats. Significant levels of some plasmalogens were still retained in moose and beef samples after grilling following marination with unfiltered beer-based marinades. To gain further insights underlying retention and/or loss of grilled moose and beef PC and PE plasmalogens, their molecular species compositions were also investigated.

\subsection{Effect of unfiltered beer-based marination on $p P E$ and $p P C$ molecular species composition in grilled moose meat}

Fig. 5a shows the relative distribution ( $\mathrm{nmol} \%$ ) of pPE molecular species in unmarinated grilled moose. pPE represents the major proportion of moose PE which are enriched with PUFAs [2]. Close 
(a)

plasmalogen PE molecular species in MU

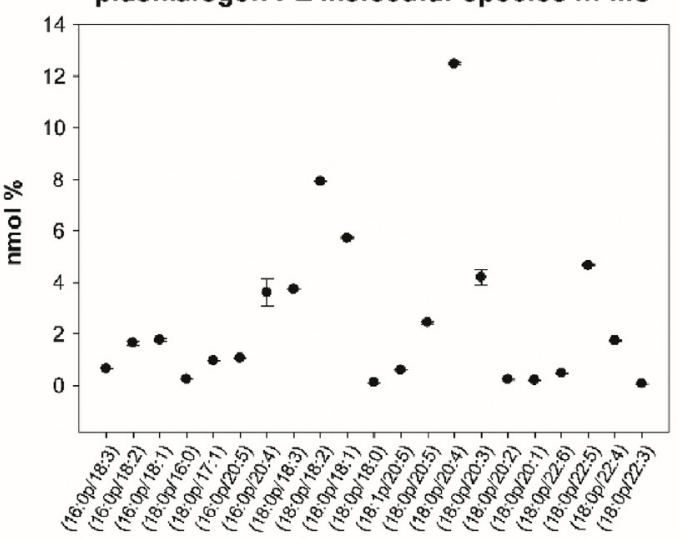

(c) PPE molecular species changes in moose (Q3)

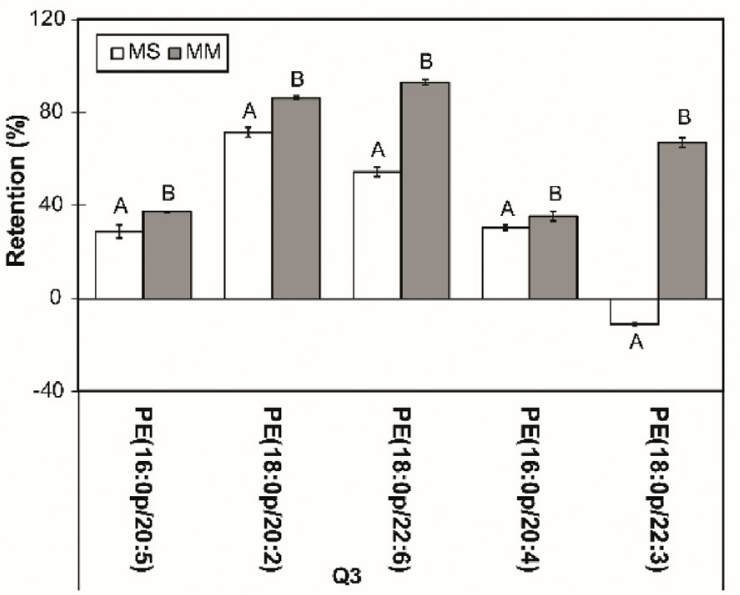

pPE molecular species changes in moose (Q1)

(e)

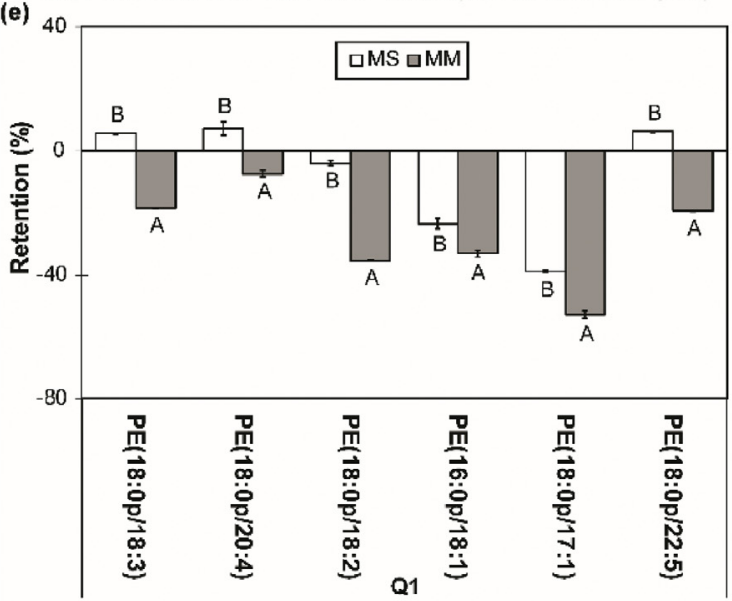

(b) Biplot-pPE molecularspecies (axes F1 and F2: $91.27 \%$ )

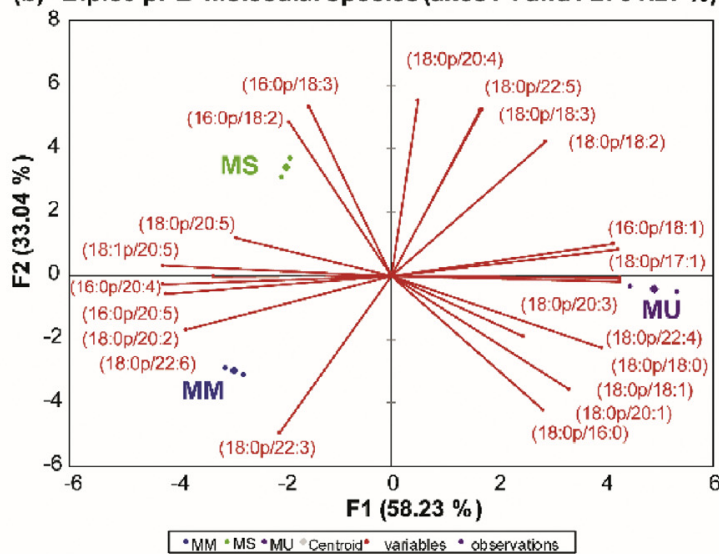

(d) pPE molecular species changes in moose (Q4)

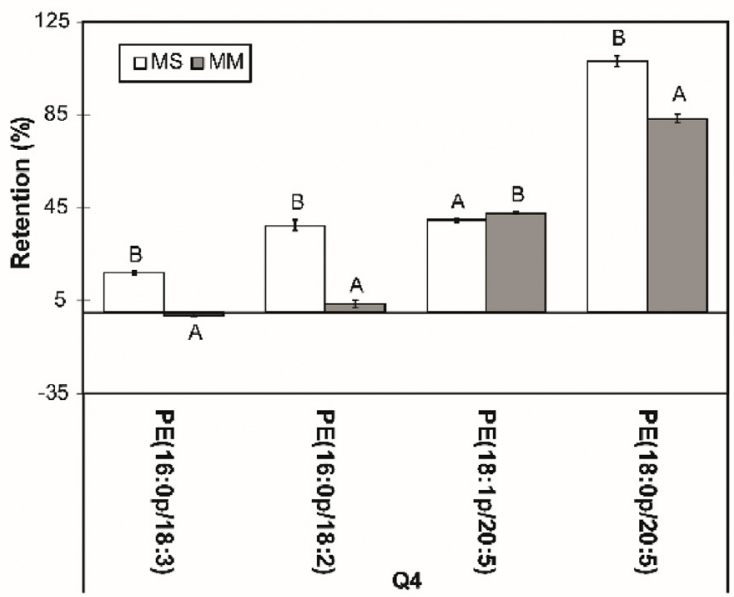

(f)

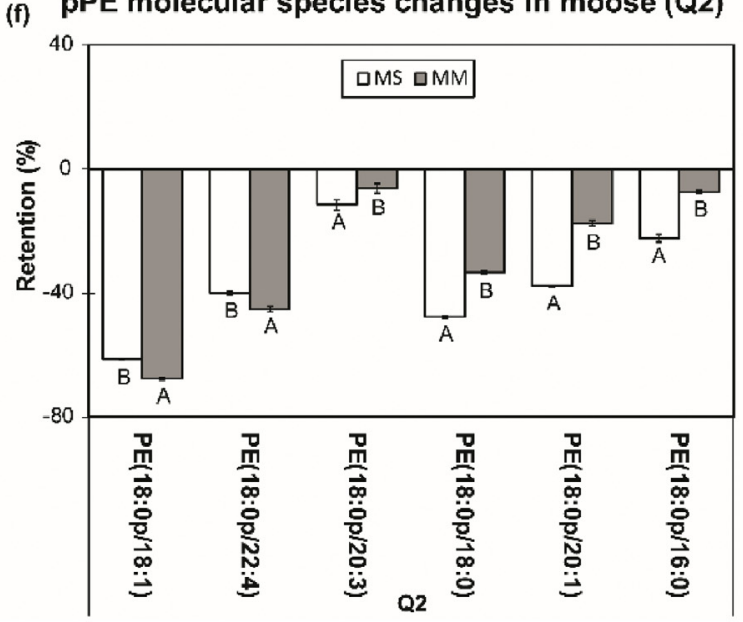

Fig. 5. Marination effect on $p P E$ species in grilled moose. Values in bar charts and dot plot represent means \pm standard errors. Means accompanied by different letters are significantly different at LSD $(P<0.05 ; n=3)$. a) Dot plot showing distribution of pPE species. $b)$ Principal component analysis showing clustering of $p P E$ species. $c-f$ ) Bar chart showing retention level (\%) of pPE in marinated moose. [MU] = unmarinated grilled moose; [MM] $=$ Indian Session ale unfiltered beer-based marinated grilled moose; [MS] = wheat Ale unfiltered beer-based marinated grilled moose. PE $=$ Phosphatidylethanolamine; $p=$ Plasmalogen. 
evaluation of the molecular composition showed that $\mathrm{C} 18$ vinyl-ether linked molecular species enriched with C20:4, C18:2, C18:1 and C22:5 fatty acids predominate grilled moose pPE profile (Fig. $5 a)[33,34]$. Principal component analysis (PCA) was conducted using concentrations of pPE molecular species and explains $91.3 \%$ of the total variation present in the data set (see Fig. 5b). PCA biplot showed a clear separation of grilled moose samples, where the unmarinated (MU) samples segregated in the positive quadrants of component 1 (F1) and the marinated samples (MM, MS) distinctly grouped in the negative quadrants (F2). The MM and MS samples clustered together with $\mathrm{C} 18$ and $\mathrm{C} 16$ vinylether linked molecular species enriched with PUFA, such as C22:6 ( $\omega 3$ docosahexaenoic acid, DHA), C22:3, C20:5 ( $\omega 3$ eicosapentaenoic acid, EPA), C20:4 ( $\omega 6$ arachidonic acid, AA) and C20:2 in MM samples, and C20:5 (EPA), C18:3 ( $\omega 3 \alpha$-linolenic acid, ALA) and C18:2 ( $\omega 6$ linoleic acid, LA) in MS samples. The \% retention levels of these species in MM and MS compared with MU (control) samples was also calculated (Fig. $5 \mathrm{c}-\mathrm{d}$ and Fig. S1a). We observed up to $100 \%$ retention of $18: 0 \mathrm{p} / 22: 6$ and 18:0p/20:5 enriched PUFA molecular species in marinated grilled moose samples (Fig. $5 c-d$ and Fig. S1a). Conversely, pPE molecular species grouped with MU samples (positive F1 quadrants) were generally enriched in MUFA (16:0p/18;1; 18:0p/17:1; 18:0p/18:1; 18:0p/20:1) and saturated fatty acid (SFA) (18:0p/18:0; 18:0p/16:0) molecular species (See Fig. $5 \mathrm{~b}, \mathrm{e}-\mathrm{f}$ and Fig. S1a). These results appear to suggest retention of essential PUFA-enriched plasmalogen species in marinated moose meat due to possible suppression of oxidative/hydrolytic degradation by antioxidants in the beer-based marinades applied to meats before grilling as evidenced by positive correlations $(P<0.05)$ between preserved PUFAenriched $\mathrm{pPE}$ species including 16:0p/20:5, 18:0p/ $20: 2,18.0 \mathrm{p} / 22: 6,16: 0 \mathrm{p} / 20: 4,16: 0 \mathrm{p} / 18: 2,18: 0 \mathrm{p} / 20: 5$ and 18:1p/20:5 and antioxidants $\left(\right.$ TAA $^{\mathrm{a}}: \mathrm{r}=0.95^{* *}$, $0.98^{* *}, 0.92^{* *}, 0.61,0.53,0.15,0.51$ and $\left.0.99 * *\right)$ and polyphenols (TPC: $\mathrm{r}=0.57,0.73 *, 0.47,0.36,-0.19$, $0.74^{*}, 0.63$ and $\left.0.74^{*}\right)$ and oxygenated terpenes ( $\sum \mathrm{OT}: \mathrm{r}=0.82^{* *}, 0.80^{* *}, 0.58,0.50,0.34,0.27,0.57$ and $0.84^{* *}$ ) in marinated grilled moose samples juxtaposed by negative correlations with total oxidation levels (TOS: $\mathrm{r}=-0.89^{* *},-0.94 * *,-0.90^{* *}$, $-0.55,-0.61,0.02,-0.62$ and $-0.88^{* *}$, see Table 1 ). Complementing these, strong correlations were observed between lipophilic and hydrophilic antioxidants, polyphenols, oxidation status and oxygenated terpene compounds in the marinades which appear to suggest that these antioxidant phytochemicals may be associated with the
Table 1. Pearson's correlation coefficients showing relationships between antioxidant activity, phenolic content, oxygenated terpenes, oxidation status and preserved plasmalogen PE molecular species in grilled moose and beef.

\begin{tabular}{llllll}
\hline Moose_pPE & TAA $^{\mathrm{a}}$ & TPC & TAA $^{\mathrm{b}}$ & $\sum \mathrm{OT}$ & TOS \\
\hline $16: 0 \mathrm{p} / 20: 5$ & $0.95^{* *}$ & 0.57 & $0.98^{* *}$ & $0.82^{* *}$ & $-0.89^{* *}$ \\
$18: 0 \mathrm{p} / 20: 2$ & $0.98^{* *}$ & $0.73^{*}$ & $0.96^{* *}$ & $0.80^{* *}$ & $-0.94^{* *}$ \\
$18: 0 \mathrm{p} / 22: 6$ & $0.92^{* *}$ & 0.47 & $0.93^{* *}$ & 0.58 & $-0.90^{* *}$ \\
$16: 0 \mathrm{p} / 20: 4$ & 0.61 & 0.36 & 0.65 & 0.50 & -0.55 \\
$18: 0 \mathrm{p} / 22: 3$ & 0.53 & -0.19 & $0.68^{*}$ & 0.34 & -0.61 \\
$16: 0 \mathrm{p} / 18: 2$ & 0.15 & $0.74^{*}$ & -0.02 & 0.27 & 0.02 \\
$18: 0 \mathrm{p} / 20: 5$ & 0.51 & 0.63 & 0.46 & 0.57 & -0.62 \\
$18: 1 \mathrm{p} / 20: 5$ & $0.99^{* *}$ & $0.74^{*}$ & $0.97^{* *}$ & $0.84^{* *}$ & $-0.88^{* *}$ \\
\hline Beef_pPE & $\mathrm{TAA}^{\mathrm{a}}$ & $\mathrm{TPC}$ & $\mathrm{TAA}^{\mathrm{b}}$ & $\sum \mathrm{OT}$ & $\mathrm{TOS}$ \\
\hline $18: 0 \mathrm{p} / 18: 1$ & $0.97^{* *}$ & $0.72^{*}$ & $0.87^{* *}$ & $0.89^{* *}$ & $-0.83^{* *}$ \\
$18: 0 \mathrm{p} / 17: 1$ & $0.84^{* *}$ & 0.29 & $0.71^{*}$ & 0.64 & -0.60 \\
$18: 0 \mathrm{p} / 18: 2$ & 0.58 & 0.23 & 0.66 & 0.32 & -0.48 \\
$16: 0 \mathrm{p} / 18: 2$ & 0.64 & -0.17 & 0.46 & 0.40 & -0.33 \\
$16: 0 \mathrm{p} / 18: 1$ & $0.82^{* *}$ & 0.25 & $0.67^{*}$ & 0.58 & -0.53 \\
$18: 0 \mathrm{p} / 18: 3$ & $0.81^{* *}$ & 0.27 & $0.67^{*}$ & 0.63 & -0.57 \\
$18: 0 \mathrm{p} / 22: 4$ & 0.36 & 0.28 & -0.23 & -0.18 & 0.12 \\
$18: 0 \mathrm{p} / 18: 0$ & -0.24 & 0.43 & -0.02 & 0.03 & -0.14 \\
\hline
\end{tabular}

Values with ${ }^{*}$ : significant correlation $(P<0.05)$; ${ }^{* *}$ : significant correlation $(P<0.01) . \sum$ OT $=$ linalool + endo-borneol + terpinen-4-ol + terpineol + carvacrol + carvacrol isomer-1+ carvacrol isomer-2. $\sum \mathrm{OT}=$ summation of oxygenated terpenes; TAA $=$ Total antioxidant activity; TPC $=$ Total phenolic content; TOS = Total oxidant status; $\mathrm{P}=$ Phosphatidyl; $\mathrm{E}=$ Ethanolamine. $\mathrm{p}=$ Plasmalogen; ${ }^{\mathrm{a}}=$ ABTS antioxidant activity; ${ }^{\mathrm{b}}=$ FRAP antioxidant activity

preservation of pPE in grilled moose (Table S1). However, it must be pointed out that though the correlations show strong associations between antioxidants, polyphenols and oxygenated terpenes and PUFA pPE species oxidation in grilled meat samples, they do not explain cause or effects of these antioxidant phytochemicals on oxidation but rather suggest there appears to be a relationship between marination and preservation of PUFA pPE species, and further work with larger sample size may be required to fully investigate this relationship. Significantly, these results appear to be consistent with the increased in antioxidant activities, phenolic contents and associated reduction in oxidation levels (TOS) of unfiltered beer-based marinated grilled moose compared to unmarinated controls observed in our previous studies $[6,11]$. The unfiltered session ales used in formulating the marinades evaluated in current study were crafted from barley grains and hops rich in polyphenols including hydroxybenzoic and hydroxycinnamic acids which have antioxidant properties [35]. The antioxidant activity of marinades may also be attributed to herbs and spices including oregano, garlic, black pepper, parsley, mustard, and olive oil used to formulate the marinades, which contain antioxidants, polyphenols and oxygenated terpenes 
(a)

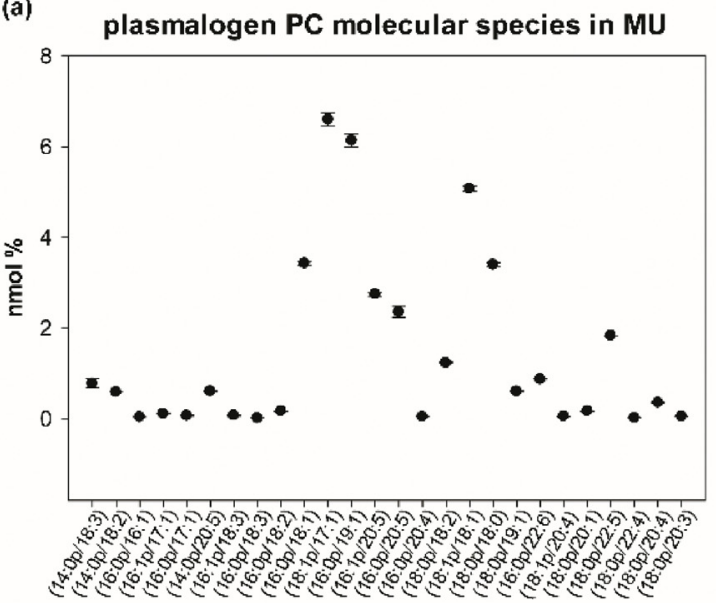

(c)

pPC molecular species changes in moose (Q1)

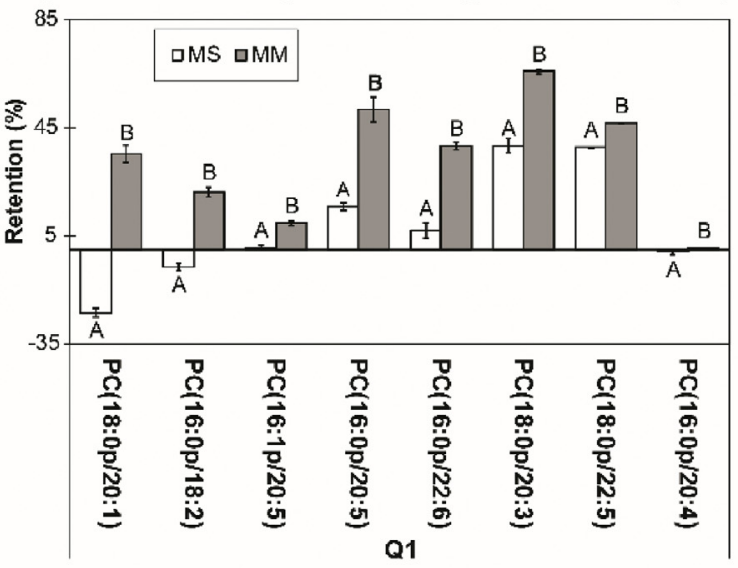

(e)

pPC molecular species changes in moose (Q3)

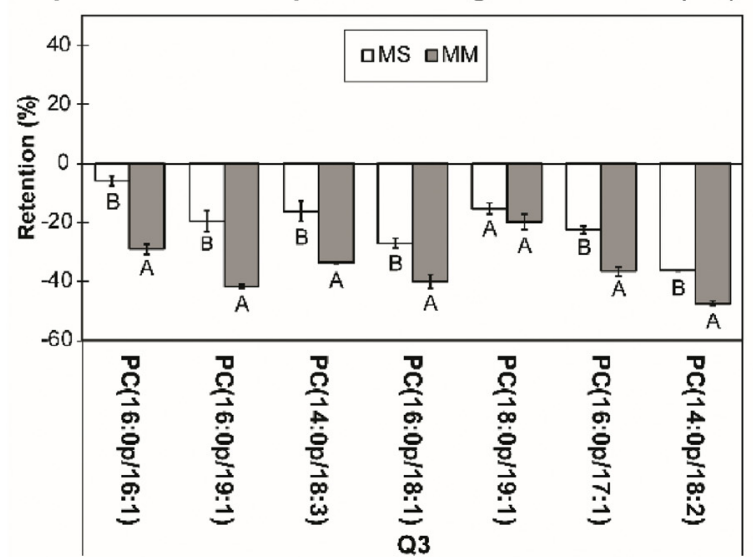

(b)

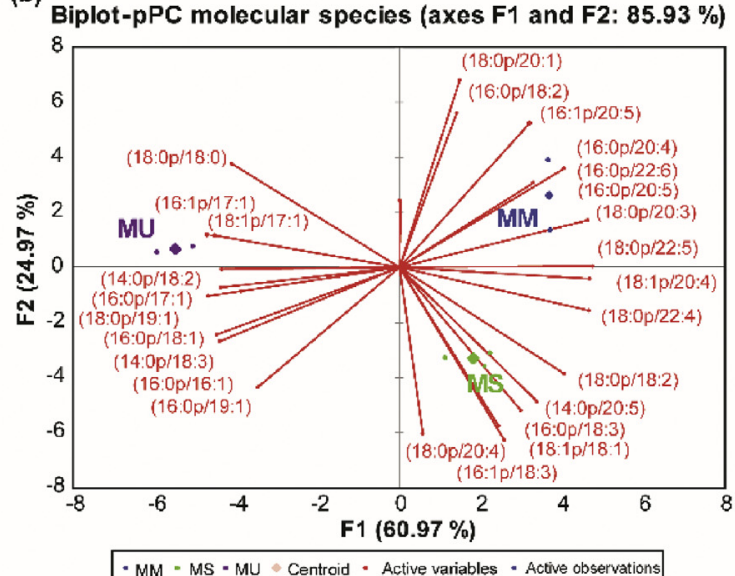

(d)

pPC molecular species changes in moose (Q2)

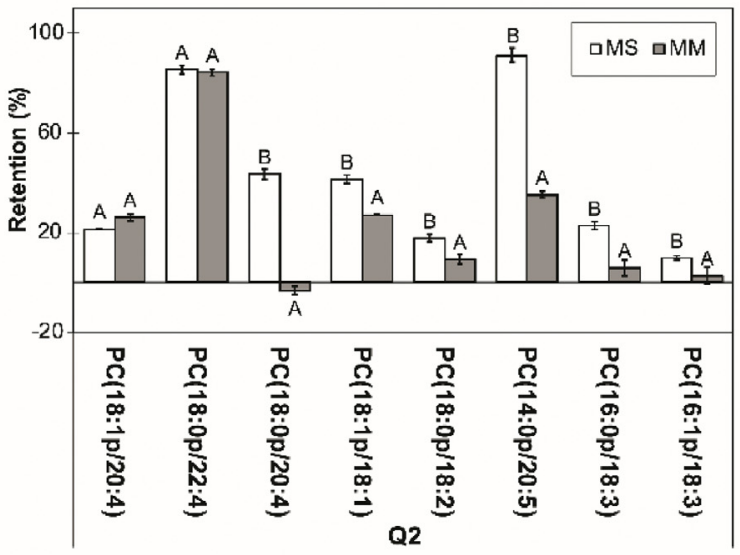

(f)

pPC molecular species changes in moose (Q4)

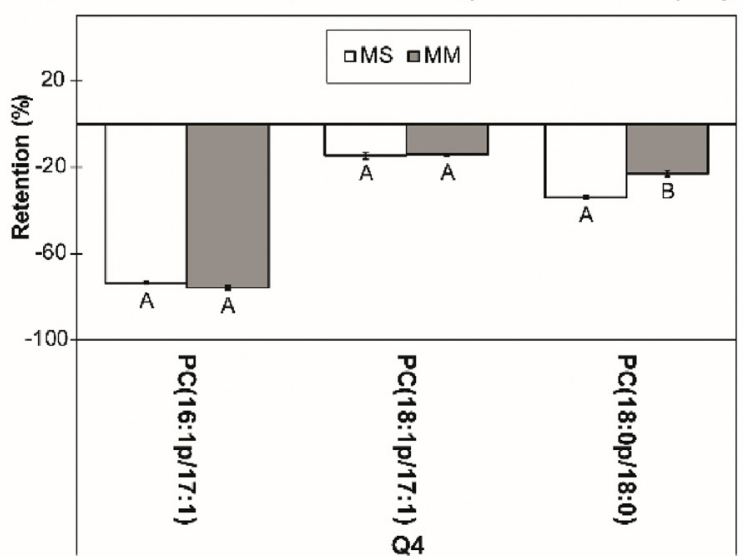

Fig. 6. Marination effect on $p P C$ species in grilled moose. Values in bar charts and dot plot represent means \pm standard errors. Means accompanied by different letters are significantly different at $\operatorname{LSD}(P<0.05 ; n=3)$. a) Dot plot showing distribution of pPC species. b) Principal component analysis showing clustering of pPC species. c-f) Bar chart showing retention level (\%) of pPC in marinated moose. [MU] = unmarinated grilled moose; [MM] $=$ Indian Session ale unfiltered beer-based marinated grilled moose; $[\mathrm{MS}]=$ wheat Ale unfiltered beer-based marinated grilled moose. PC $=$ Phosphatidylcholine; $p=$ Plasmalogen. 
including quercetin, allicin, caffeic acid, carnosol, rosemanol, pinene, geraniol, limonene, carvone, terpineol, endo-borneol, carvacrol, oleuropein and kaempferol responsible for their antiradical activities $[6,10,36]$.

The same was observed for pPC species (Fig. 6). PCA performed with $\mathrm{pPC}$ molecular species showed that marinated samples (MM, MS) clustered in the positive quadrants of component 1 (F1) whereas the unmarinated ones (MU) distinctly grouped in the negative quadrants (F2) of the biplot (Fig. 6b). PCA output represents $85.9 \%$ of the total variation present in the data set. The results showed C18, C16 and $\mathrm{C} 14$ vinyl-ether linked molecular species enriched with PUFAs (C22:6, C22:5, C22:4, C20:5, C20:4, C20:3, C18:3 and C18:2) clustered marinated grilled moose samples (MM and MS) in quadrants 1 and 2 respectively of biplot. Conversely, C18, C16 and C14 molecular species enriched in SFA (C18:0) and MUFA (C16:1, C17:1, C18:1 and C19:1) grouped the control samples (MU) in quadrants 3 and 4 of the biplot (Fig. 6 b). The $\%$ retention levels were also calculated and showed up to $90 \%$ retention of these PUFA-enriched pPC species in marinated grilled moose samples (Fig. 6c-f and Fig. S1b). As alluded previously, the herbs, spices and unfiltered beers used to formulate the marinades evaluated in current study are enriched with natural antioxidants that have been used to preserve against oxidative degradative in cooked and raw meats [37, 38]. Furthermore, India session beer is a dark ale and may contain melanoidins (derived from melanoidin malts responsible for its dark rich color) which are excellent natural dietary antioxidants [39]. Wheat ale beer contains lemon and lime (responsible for its refreshing, fruity and citrusy flavor) which are also well-known excellent sources of dietary antioxidants. The herbs, spices and unfiltered beers are known to be excellent sources of polyphenolic compounds which function as antioxidants by donating hydrogen radicals for pairing with lipid radicals formed during lipid oxidation processes [10]. Similar to pPE, the preserved pPC species including PUFA enriched essential fatty acids; LA (C18:2 $\omega 6)$, ALA (C18:3 $\omega 3)$, dihomo- $\gamma$-linolenic acid

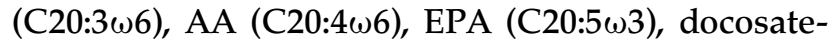
traenoic acid: DTA (C22:4 $\omega 6)$, docosapentaenoic

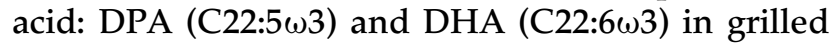
moose meats were generally positively correlated with lipophilic antioxidants $\left(\mathrm{LAA}^{\mathrm{a}}\right.$ : $\mathrm{r}=0.17-$ $\left.0.97^{* *}\right)$, carvacrol $\left(\mathrm{r}=0.1-0.99^{* *}\right)$ and hydrophilic polyphenols (LPC: $r=0.26-0.92^{* *}$ ) present in the unfiltered beer-based marinades, and negatively correlated with hydrophilic oxidation status (TOS: $r$ $=-0.07$ to $-0.86^{* *}$, see Table S2). These
Table 2. Pearson's correlation coefficients showing relationships between antioxidant activities, phenolic contents, oxygenated terpenes, oxidation status and preserved plasmalogen PC molecular species in grilled moose and beef.

\begin{tabular}{|c|c|c|c|c|c|}
\hline Moose_pPC & $\mathrm{TAA}^{\mathrm{a}}$ & ТPC & $\mathrm{TAA}^{\mathrm{b}}$ & $\sum \mathrm{OT}$ & TOS \\
\hline $18: 0 \mathrm{p} / 20: 1$ & $-0.17^{* *}$ & 0.55 & -0.35 & -0.01 & 0.31 \\
\hline $16: 0 \mathrm{p} / 18: 2$ & $-0.67^{*}$ & 0.45 & -0.13 & 0.02 & -0.04 \\
\hline $16: 1 \mathrm{p} / 20: 5$ & 0.25 & $0.80 * *$ & 0.12 & 0.42 & -0.14 \\
\hline $16: 0 \mathrm{p} / 20: 5$ & 0.51 & $0.96^{*}$ & 0.33 & 0.51 & -0.33 \\
\hline $16: 0 \mathrm{p} / 22: 6$ & 0.38 & $0.79 *$ & 0.20 & 0.47 & -0.11 \\
\hline $18: 0 \mathrm{p} / 20: 3$ & $0.74^{*}$ & $0.99 * *$ & 0.61 & 0.66 & -0.61 \\
\hline $18: 0 \mathrm{p} / 22: 5$ & $0.88^{* *}$ & $0.94 * *$ & $0.77^{*}$ & $0.74^{*}$ & $-0.77^{*}$ \\
\hline $16: 0 \mathrm{p} / 20: 4$ & -0.13 & -0.01 & -0.05 & -0.01 & -0.15 \\
\hline $18: 1 \mathrm{p} / 20: 4$ & $0.89 * *$ & $0.93 * *$ & $0.77 *$ & $0.72 *$ & $-0.73^{*}$ \\
\hline $18: 0 \mathrm{p} / 22: 4$ & $0.96^{* *}$ & $0.88^{* *}$ & $0.88^{* *}$ & $0.80 * *$ & $-0.82 * *$ \\
\hline $18: 0 \mathrm{p} / 20: 4$ & 0.55 & -0.10 & 0.64 & 0.35 & -0.54 \\
\hline 18:1p/18:1 & $0.97 * *$ & $0.67^{*}$ & $0.96 * *$ & $0.84^{* *}$ & $-0.88^{* *}$ \\
\hline 18:0p/18:2 & $0.92 * *$ & 0.52 & $0.90 * *$ & $0.70 *$ & $-0.80 * *$ \\
\hline $14: 0 \mathrm{p} / 20: 5$ & $0.88^{*}$ & 0.41 & $0.93 * *$ & $0.80 * *$ & $-0.80 * *$ \\
\hline $16: 0 \mathrm{p} / 18: 3$ & $0.85^{* *}$ & 0.30 & $0.92 * *$ & 0.65 & $-0.84^{* *}$ \\
\hline 16:1p/18:3 & $0.75^{*}$ & 0.29 & $0.82 * *$ & $0.70^{*}$ & $-0.71^{*}$ \\
\hline Beef_pPC & $\mathrm{TAA}^{\mathrm{a}}$ & TPC & $\mathrm{TAA}^{\mathrm{b}}$ & $\sum \mathrm{OT}$ & TOS \\
\hline $18: 0 \mathrm{p} / 20: 3$ & $0.72 *$ & 0.01 & 0.53 & 0.48 & -0.38 \\
\hline $18: 0 \mathrm{p} / 20: 1$ & -0.38 & -0.67 & -0.50 & -0.42 & 0.47 \\
\hline $18: 0 \mathrm{p} / 18: 2$ & 0.11 & -0.52 & -0.12 & -0.11 & 0.29 \\
\hline $18: 0 \mathrm{p} / 22: 5$ & 0.34 & -0.38 & 0.13 & 0.01 & 0.03 \\
\hline $14: 0 \mathrm{p} / 20: 5$ & -0.01 & $-0.68^{*}$ & -0.20 & -0.27 & 0.36 \\
\hline $14: 0 \mathrm{p} / 18: 3$ & -0.15 & $-0.75^{*}$ & -0.27 & -0.42 & 0.44 \\
\hline 18:0p/19:1 & 0.34 & -0.33 & 0.15 & 0.05 & 0.06 \\
\hline $18: 1 \mathrm{p} / 20: 4$ & -0.39 & $-0.90 * *$ & -0.50 & -0.63 & $0.69^{*}$ \\
\hline $16: 0 \mathrm{p} / 18: 3$ & -0.33 & $-0.88 * *$ & -0.48 & -0.56 & 0.63 \\
\hline $16: 1 \mathrm{p} / 18: 3$ & -0.3 & $-0.88^{* *}$ & -0.50 & -0.60 & 0.66 \\
\hline $16: 0 \mathrm{p} / 18: 2$ & 0.45 & -0.23 & 0.31 & 0.13 & -0.11 \\
\hline $16: 0 \mathrm{p} / 17: 1$ & 0.38 & $0.86^{* *}$ & 0.47 & 0.63 & $-0.67^{*}$ \\
\hline $18: 0 \mathrm{p} / 18: 0$ & $0.95^{* *}$ & $0.67^{*}$ & $0.85^{* *}$ & $0.89 * *$ & $-0.84 * *$ \\
\hline $18: 0 \mathrm{p} / 20: 4$ & 0.62 & 0.30 & 0.50 & 0.51 & -0.38 \\
\hline $18: 0 \mathrm{p} / 22: 4$ & $0.69^{*}$ & 0.62 & 0.48 & $0.84 * *$ & -0.61 \\
\hline 18:1p/17:1 & $0.96 * *$ & 0.57 & $0.85 * *$ & $0.81 * *$ & $-0.78^{*}$ \\
\hline $16: 0 \mathrm{p} / 19: 1$ & $0.89 * *$ & $0.96^{* *}$ & $0.87 * *$ & $0.96^{* *}$ & $-0.94 * *$ \\
\hline $16: 0 \mathrm{p} / 16: 1$ & $0.72^{*}$ & $0.98 * *$ & $0.75^{*}$ & $0.87 * *$ & $-0.87 * *$ \\
\hline 18:1p/18:1 & $0.92 * *$ & 0.40 & $0.70 *$ & $0.80^{*}$ & -0.65 \\
\hline $16: 0 \mathrm{p} / 18: 1$ & $0.74 *$ & $0.99 * *$ & $0.81 * *$ & $0.84^{* *}$ & $-0.87 * *$ \\
\hline
\end{tabular}

Values with $*$ : significant correlation $(P<0.05)$; $* *$ : significant correlation $(P<0.01) . \Sigma$ OT $=$ linalool + endo-borneol + terpinen-4-ol + terpineol + carvacrol + carvacrol isomer-1+ carvacrol isomer-2. $\sum \mathrm{OT}=$ summation of oxygenated terpenes; $\mathrm{TAA}=$ Total antioxidant activity; TPC $=$ Total phenolic content; TOS = Total oxidant status; $\mathrm{P}=$ Phosphatidyl; $\mathrm{C}=$ Choline. ${ }^{\mathrm{a}}=$ ABTS antioxidant activity; ${ }^{\mathrm{b}}=$ FRAP antioxidant activity; $\mathrm{p}=$ Plasmalogen.

associations were collaborated by similar correlations trends though comparatively weaker were between the preserved pPC species, and antioxidants, polyphenols and oxygenated terpenes in the marinades evaluated (Table 2). Whilst no data exist in the literature on plasmalogen molecular species composition in grilled moose meats, these correlations were in line with the decreased oxidation status/levels of unfiltered beer based-marinated grilled moose samples resulting possibly from the 
antiradical activities of unfiltered beer based marinades formulated from antioxidant-rich herbs, spices and unfiltered beers [6, 11]. Significantly, while these correlations do not explain the causes or effects of antioxidants, polyphenols and oxygenated terpenes on oxidative/hydrolytic degradation of pPC species, they appear to suggest a relationship between the preservation of these species in grilled moose meats and unfiltered beer-based marinades, and further work with larger sample size will be required to further investigate this relationship. Although the total plasmalogen content ( $\mathrm{mg} / \mathrm{g}$ meat) is reduced in marinated grilled moose samples (Fig. $3 \mathrm{~g}$ ), the molecular species linked to those plasmalogens are different, and our results appear to support the potential of unfiltered beer-based marinades to preserve significant numbers of $\mathrm{pPE}$ (12 out 21$)$ and pPC (16 out of 26$)$ species respectively (Fig. 5 and 6, also see Fig. S1a-b). Plasmalogens are reservoirs of PUFAs ARA in cells and as endogenous antioxidants which protect other cellular biomolecules from oxidative damage [40]. Oxidation of plasmalogens in moose meats during grilling could lead to formation of toxic secondary oxidation compounds and development of objectionable changes in meat quality, i.e., off-flavors, offodors and discoloration and formation of toxic secondary oxidation compounds [41].

In view of the known health-promoting benefits associated with consumption of plasmalogens and essential fatty acids, marinating moose meat with beer-based marinades before grilling could preserve a number of $\mathrm{pPC}$ and $\mathrm{pPE}$ lipids including those enriched in essential $\omega 3$ and $\omega 6$ fatty acids and increase their dietary access and consumption.

\subsection{Effect of unfiltered beer-based marination on $p P E$ and $p P C$ molecular species composition in grilled beef}

As in moose meat, plasmalogens constituted the major PE subclass in grilled beef (Fig. $4 a-c)$. The relative distribution (nmol \%) of pPE molecular species in unmarinated grilled beef is shown in Fig. 7a. C18 and C16 vinyl-ether linked molecular species enriched with PUFA C20:4, C18:2, and C18:3 fatty acids predominate $\mathrm{pPE}$ profile of grilled beef [25]. Following PCA, pPE molecular species successfully grouped marinated grilled beef samples (BM and BS) in quadrants 1 and 3 of PCA biplot, whereas unmarinated samples (BU) clustered in quadrant 2 (Fig. 7b). This grouping explained 83.7\% of the total variation present in the data set. As a trend, PUFA enriched species including 16:0p/18:3, 18:0p/20:4, 16:0p/20:4 and 18:0p/20:5 clustered BU samples in quadrant 2, and BS samples in quadrant 1 of biplot respectively (Fig. $7 \mathrm{~b}$ ). These species were with two exceptions (18:0p/18:0 and 18:0p/22:4) lost in marinated grilled beef samples (BS and BM) compared to unmarinated control samples possibly as a result of oxidative/hydrolytic degradative processes during grilling (Fig. $7 \mathrm{c}-\mathrm{d}$ and Fig. S1c). The remaining species including MUFA- (18:0p/17:1, 18:0p/18:1, and 16:0p/18:1) and PUFA-enriched (18:0p/18:3, 18:0p/18:2 and 16:0p/18:2) pPE molecular species were grouped in quadrant 3 with $\mathrm{BM}$ samples (Fig. 7b). The results further show there is up to $24 \%$ retention of these pPE molecular species in marinated grilled beef (Fig. $7 \mathrm{e}-\mathrm{f}$ and Fig. S1c). This preservation could be the result of suppression of oxidative/hydrolytic degradative processes by antioxidants in the unfiltered beer-based marinades during grilling [10, 31]. As in moose, generally positive correlations between lipophilic polyphenols (LPC: $\mathrm{r}=0.44-0.93^{* *}$ ), hydrophilic antioxidants $\left(\mathrm{HAA}^{\mathrm{a}}: \mathrm{r}=0.24-0.97^{* *}\right)$, and oxygenated terpenes ( $\sum$ OT: $\mathrm{r}=-0.18-0.89^{* *}$ ) and the preserved MUFA and PUFA pPE species including 18:0p/22:4, 18:0p/ 18:3, 16:0p/18:2, 18:0p/18:2, 18:0p/18:1p, 16:0p/18:1, and 18:0p/17:1 in marinated grilled beef appear to suggest a possible association between preservation of these species in grilled beef samples and antioxidants, polyphenols and oxygenated terpenes present in the marinades (Table S1 and Table 1). Significantly, these positive correlations were contrasted by negative correlations between the preserved pPE species and hydrophilic oxidation levels (HOS: $\mathrm{r}=-0.55--0.84^{* *}$, see Table $\mathrm{S} 1$ and Table 1) of marinated grilled beef samples, which is consistent with the reduction of oxidation possibly by antioxidants in marinades [7, 11, 37]. However, these correlations by themselves alone cannot explain the causes or effect of antioxidants on suppression of oxidative/hydrolytic degradation of PUFA and MUFA pPE species in marinated grilled beef samples, and further work may be required to fully elucidate this relationship. Notwithstanding, the herbs and spices used in formulating the unfiltered beer-based marinades evaluated in current study are known to contain phytochemical antioxidants with excellent antioxidant/antiradical activities, and have been shown in to suppress lipid oxidation and preserve quality of raw and cooked meats [31, 37, 42]. Taken altogether, although a greater number of pPE molecular species including long chain PUFA pPE species appear to have been degraded in marinated grilled beef samples compared to marinated grilled moose samples, three out of five species predominating $\mathrm{pPE}$ molecular profile (18:0p/18:2, 18:0p/18:3 and 16:0p/18:2) 
(a)

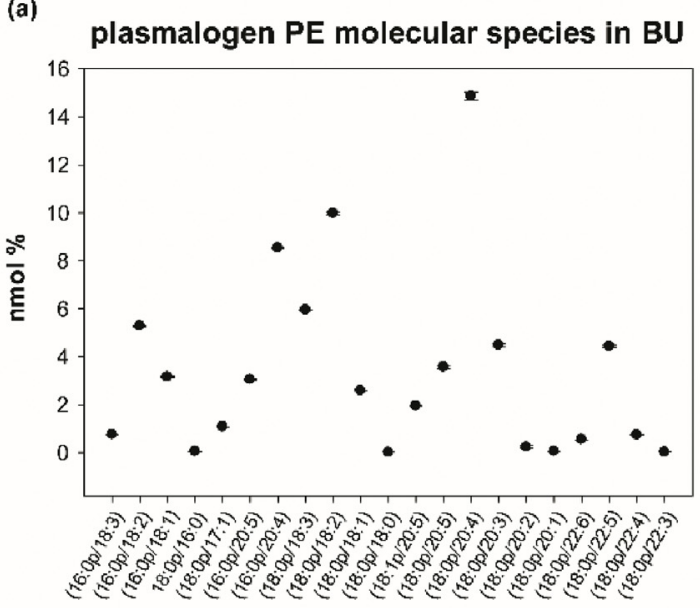

(c) pPE molecular species changes in beef (Q1)

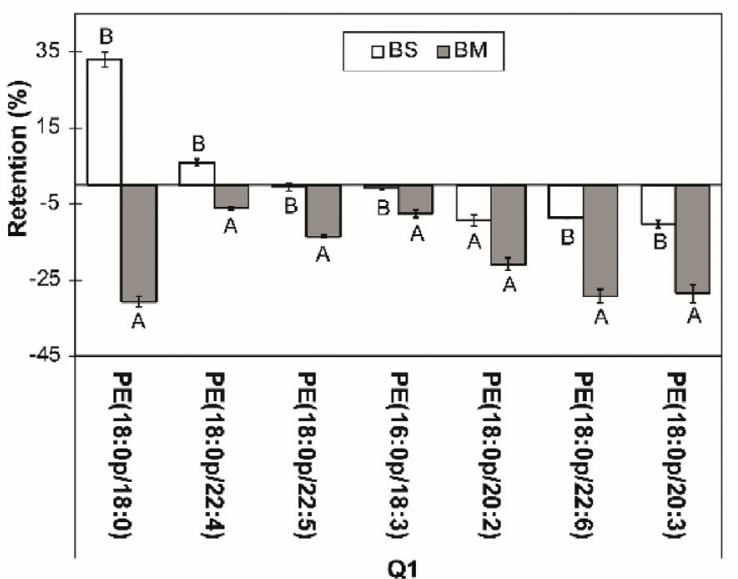

(e) pPE molecular species changes in beef (Q3)

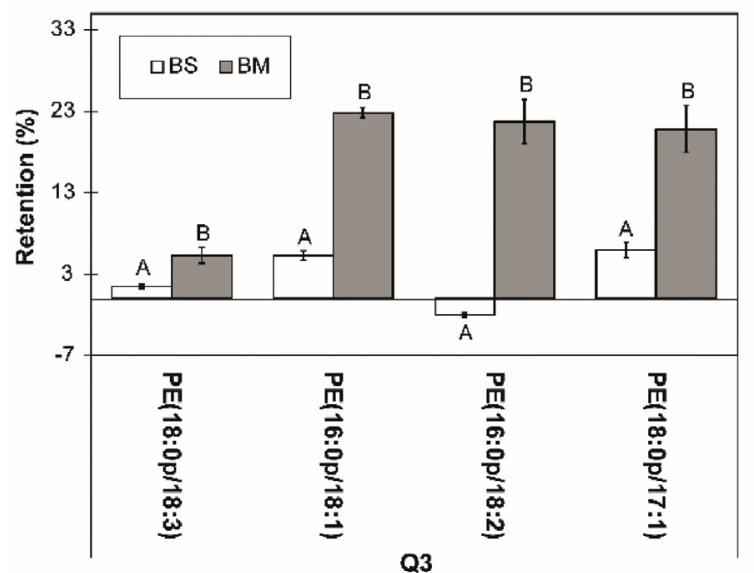

(b)

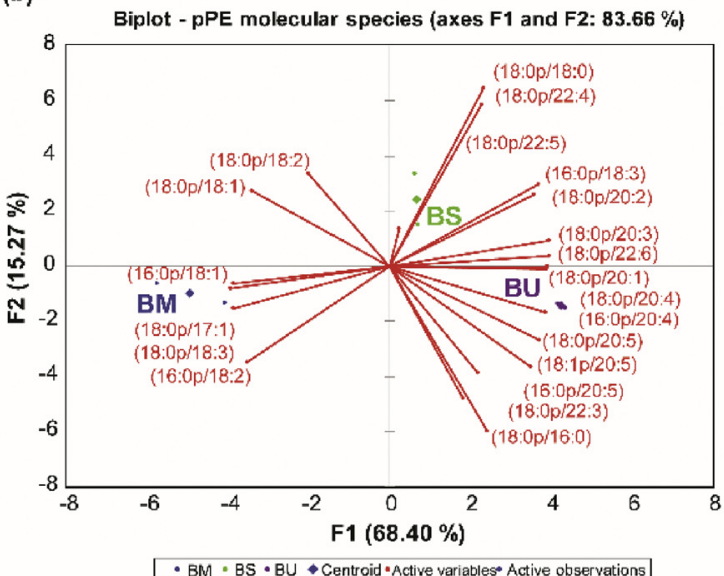

(d) pPE molecular species changes in beef (Q2)

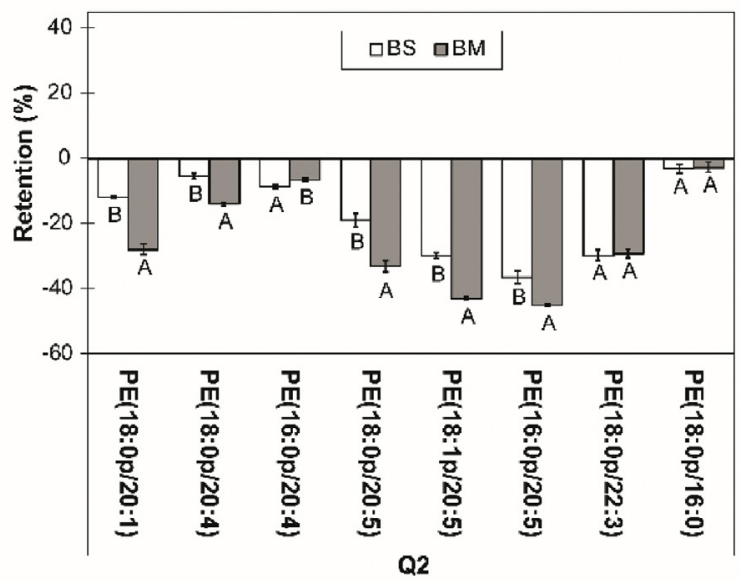

(f) pPE molecular species changes in beef (Q4)

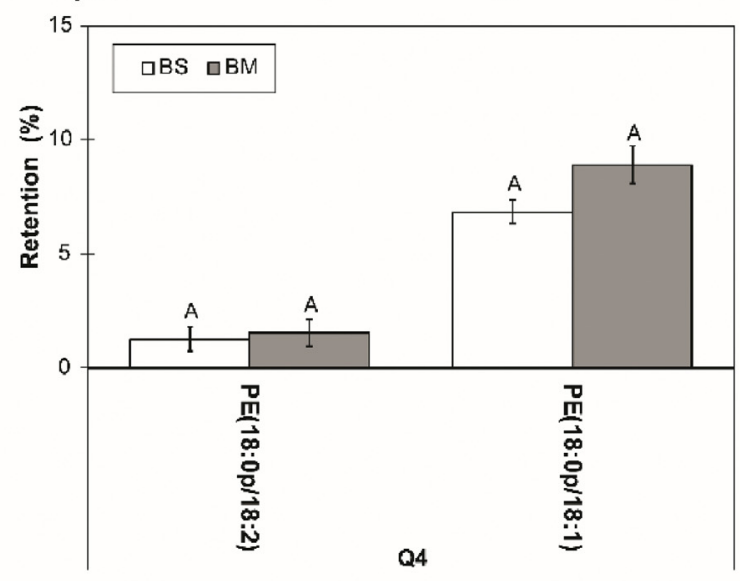

Fig. 7. Marination effect on pPE species in grilled beef. Values in bar charts and dot plot represent means \pm standard errors. Means accompanied by different letters are significantly different at $L S D(P<0.05 ; n=3)$. a) Dot plot showing distribution of pPE species. $b)$ Principal component analysis showing clustering of pPE species. $c-f)$ Bar chart showing retention level (\%) of pPE in marinated beef. [BU] $=$ unmarinated grilled beef; [BM] $=$ Indian Session ale unfiltered beer-based marinated grilled beef; $[B S]=$ wheat Ale unfiltered beer-based marinated grilled beef. PE $=$ Phosphatidylethanolamine; $p=$ Plasmalogen. 
(a)

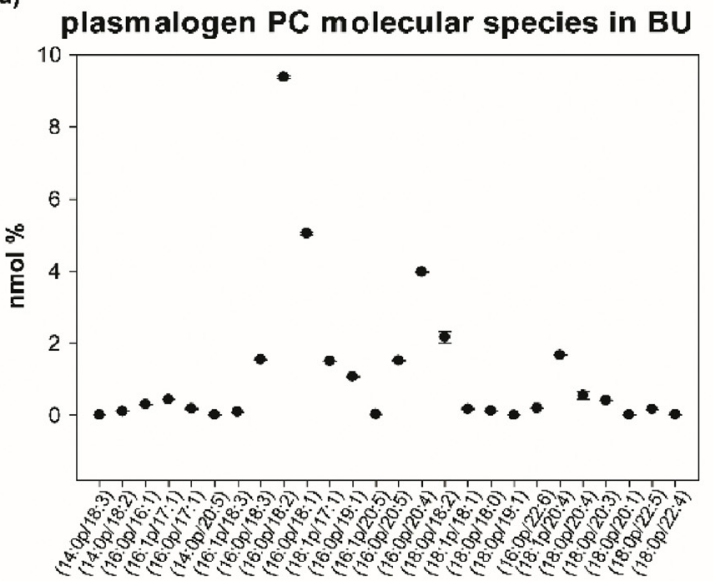

(c)

pPC molecular species changes in beef (Q1)

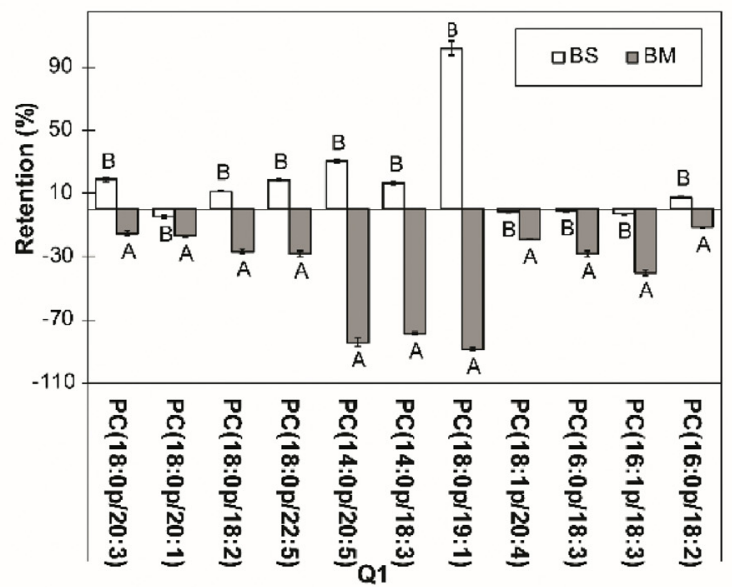

(b)

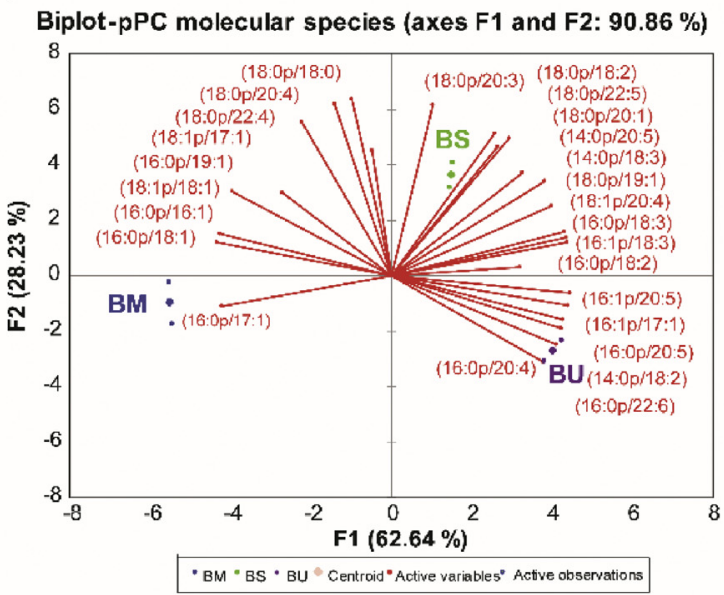

(d)

pPC molecular species changes in beef (Q2)

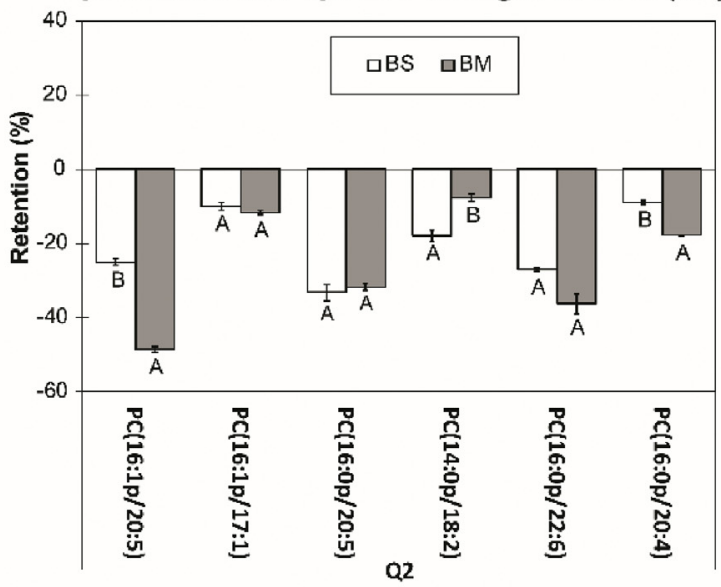

(e)

pPC molecular species changes in beef (Q3/Q4)

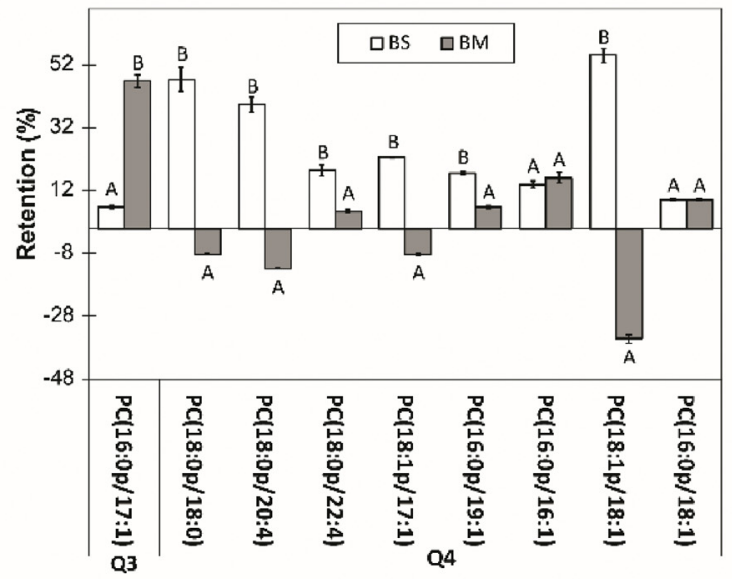

Fig. 8. Marination effect on pPC species in grilled beef. Values in bar charts and dot plot represent means \pm standard errors. Means accompanied by different letters are significantly different at $L S D(P<0.05 ; n=3)$. a) Dot plot showing distribution of pPC species. $b)$ Principal component analysis showing clustering of $p P C$ species. $c-f)$ Bar chart showing retention level (\%) of $p P C$ in marinated beef. $[B U]=$ unmarinated grilled beef; $[B M]=$ Indian Session ale unfiltered beer-based marinated grilled beef; $[B S]=$ wheat Ale unfiltered beer-based marinated grilled beef. PC $=$ Phosphatidylcholine; $p=$ Plasmalogen. 
were retained in marinated grilled beef samples (Fig. 7a, 7e-f and Fig. S1c). This is beneficial for human health since C18:3 ( $\omega 3 \alpha$-linolenic acid) and C18:2 ( $\omega 6$-linoleic acid) are essential fatty acids which cannot be biosynthesized in human body and their preservation in marinated grilled meats against degradation is of nutritional relevance. Consumption of $\omega 3$ and $\omega 6$ enriched lipids in the diet has been associated with reduced risks for coronary heart diseases owing to their cardioprotective and anti-inflammatory effects [43].

pPC molecular species composition was predominated by 16:0p/18:2, 16:0p/18:1, 16:0p/20:4 and 18:0p/18:2 (Fig. 8a) [28]. Upon PCA, C16 and C14 vinyl-ether linked PC molecular species enriched with C17:1, C20:4, C20:5, C18:2 and C22:6 fatty acids clustered BU samples in quadrant 2 of biplot (Fig. $8 b)$. Conversely, pPC species enriched with C20:3, C18:2 ( $\omega 6$ LA), C22:5, 20:5 ( $\omega 3$ EPA), C18:3 ( $\alpha-\omega 3$ ALA) and C19:1 clustered in quadrant 1 with BS samples. BM samples were grouped in quadrant 3 with 16:0p/17:1, while pPC molecular species enriched with MUFA (18:0p/17:1, 16:0p/19:1, 16:0p/ 16:1, 18:0p/18:1, and 16:0p/18:1) and PUFA (18:0p/ 20:4 and 18:0p/22:4) clustered in quadrant 4 (Fig. 8b). These groupings accounted for $90.9 \%$ of the total variance in the data set. The calculated retention levels showed up to $100 \%$ retention of pPC species that clustered in quadrants 3 and 4 of biplot with generally superior retentions in BS compared to BM samples (Fig. 8c and e and Fig. S1d). These retentions occurred concomitantly with strong correlations with antioxidants, polyphenols and oxygenated terpenes, and appear to suggest suppression of oxidative/hydrolytic degradative processes in beef samples possibly by these antioxidant phytochemicals in marinades, and is in line with the enhanced antioxidant activities, phenolics contents, oxygenated terpene contents and lowered oxidation status/levels of unfiltered beer-based marinated grilled beef compared to unmarinated controls [6, 11]. Accordingly, correlations between PUFA and MUFA pPC enriched species including 18:0p/22:4, 18:0p/20:4, 18:0p/22:5, 18:0p/20:3, 18:1p/17:1, 16:0p/ 16:1, 16:0p/19:1, etc., and antioxidants $\left(\mathrm{TAA}^{\mathrm{a}}: \mathrm{r}=\right.$ $\left.0.69 *, 0.62,0.34,0.72 *, 0.96^{* *}, 0.72 *, 0.89 * *\right)$, lipophilic polyphenols (LPC: $\mathrm{r}=0.50,0.61,0.500 .84^{* *}$, $0.99 * * 0.56,0.77 *$ respectively), oxygenated terpenes ( $\sum \mathrm{OT}: \mathrm{r}=0.84^{* *}, 0.50,0.01,0.48,0.81^{* *}, 0.87^{* *}$, $0.96^{* *}$ ) present in the marinades were positive whereas correlations between these species and lipophilic oxidation status (LOS) of marinated grilled beef were negative and ranged from $-0.12-$
$-0.96^{* *}$ suggesting a relationship possibly between beer based marination and suppression of oxidative/hydrolytic degradation of pPC species (Table 2 and Table S3). Furthermore, retention of pPE species was generally higher in BM whereas retention of pPC species was higher in BS samples. Significantly, there appears to be greater retention of PUFA enriched plasmalogen molecular species including long chain PUFA pPE and $\mathrm{pPC}$ in grilled moose compared to grilled beef samples by beerbased marination which could be due possibly to variations in intermuscular fat compositions between the meats, and further work outside the scope of current study may be required to fully elucidate these results.

In summary, although total plasmalogen content of marinated grilled beef was lower compared to unmarinated controls (Fig. 4g), marination with beerbased marinades retained 16 out of $26 \mathrm{pPC}$, and 8 out of 21 pPE species including SFA, MUFA and essential $\omega 3$ and $\omega 6$ PUFA-enriched plasmalogen species in grilled beef. Since plasmalogens constitute a rich source of essential fatty acids including arachidonic acid (C20:4) for incorporation into cellular membranes, their preservation in marinated grilled beef could be beneficial in maintaining membrane health, composition and functions [40].

\section{Conclusion}

This work demonstrates that beer-based marination was effective in preserving several important plasmalogen molecular species in grilled beef and moose meat, respectively. For example, more monounsaturated plasmalogen species were preserved in beef compared to more polyunsaturated species in grilled moose meat. Significantly, both beer-based marinades showed potential for preserving PUFA-enriched plasmalogen species including essential $\omega 3$ and $\omega 6$ enriched species in moose meats, and MUFA-enriched plasmalogen species in beef from oxidative degradative processes during grilling. In view of these findings, marination of ruminant meats with beer-based marinade formulations composed of antioxidant-rich herbs, spices and unfiltered beers could be a useful precooking technique to preserve grilled meat nutritional quality and sensory attributes while providing access to health-promoting dietary antioxidants, polyphenols and functional lipids.

\section{Conflict of interest}

The authors declare no conflict of interest. 


\section{Acknowledgement}

We acknowledge the funding provided by Memorial University of Newfoundland. We thank Dr. Yuan Tao for maintaining instruments used in our analysis.

\section{Appendix A. Supplementary data}

Supplementary data to this article can be found online at https://doi.org/10.1016/j.biomed.2013.10. 001.

\section{References}

[1] Manful CF, Vidal NP, Pham TH, Nadeem M, Wheeler E, Hamilton MC, et al. Dataset on improved nutritional quality and safety of grilled marinated and unmarinated ruminant meat using novel unfiltered beer-based marinades. Data Brief 2019;27:104801.

[2] Braverman NE, Moser AB. Functions of plasmalogen lipids in health and disease. Biochim Biophys Acta (BBA) - Mol Basis Dis 2012;1822:1442-52.

[3] Messias MCF, Mecatti GC, Priolli DG, de Oliveira Carvalho P. Plasmalogen lipids: functional mechanism and their involvement in gastrointestinal cancer. Lipids Health Dis 2018;17:41 [In eng].

[4] Yamashita S, Kanno S, Honjo A, Otoki Y, Nakagawa K, Kinoshita M, et al. Analysis of Plasmalogen Species in Foodstuffs. Lipids 2016;51:199-210.

[5] Fogerty AC, Whitfield FB, Svoronos D, Ford GL. Effect of heat on the fatty acids and aldehydes of veal meat phospholipids. 2007.

[6] Vidal NP, Manful C, Pham TH, Wheeler E, Stewart P, Keough D, et al. Novel unfiltered beer-based marinades to improve the nutritional quality, safety, and sensory perception of grilled ruminant meats. Food Chem 2020;302:125326.

[7] Alvarez-Parrilla E, Mercado-Mercado G, La Rosa LAD, Díaz JAL, Wall-Medrano A, González-Aguilar GA. Antioxidant activity and prevention of pork meat lipid oxidation using traditional Mexican condiments (pasilla dry pepper, achiote, and mole sauce). Food Sci Tech 2014; 34:371-8.

[8] Piazzon A, Forte M, Nardini M. Characterization of phenolics content and antioxidant activity of different beer types. J Agri Food Chem 2010;58:10677-83 [In eng].

[9] Shahidi F, Zhong Y. Lipid oxidation and improving the oxidative stability. Chem Soc Rev 2010;39:4067-79.

[10] Yashin A, Yashin Y, Xia X, Nemzer B. Antioxidant activity of spices and their impact on human health: A review. Antioxidants 2017;6:70 [In eng].

[11] Manful CF, Vidal NP, Pham TH, Nadeem M, Wheeler E, Hamilton MC, et al. Unfiltered beer based marinades reduced exposure to carcinogens and suppressed conjugated fatty acid oxidation in grilled meats. Food Control 2019: 107040.

[12] Folin O, Ciocalteu V. On tyrosine and tryptophane determinations in proteins. J Biol Chem 1927;73:627-50.

[13] Arnao MB, Cano A, Acosta M. The hydrophilic and lipophilic contribution to total antioxidant activity. Food Chem 2001;73: 239-44.

[14] Smyth ML, Davis JR. An examination of student cheating in the two-year college. Comm Coll Rev 2003;31:17-32.

[15] Benzie IF, Strain JJ. The ferric reducing ability of plasma (FRAP) as a measure of "antioxidant power": the FRAP assay. Anal Biochem 1996;239:70-6.

[16] Folch J, Lees M, Stanley GHS. A simple method for the isolation and purification of total lipides from animal tissues. J Biol Chem 1957;226:497-509.
[17] Nevins CP, Vierck JL, Bogachus LD, Velotta NS, CastroMunozledo F, Dodson MV. An inexpensive method for applying nitrogen evaporation to hexane-containing 24-or 96-well plates. Cytotechnology 2005;49:71-5.

[18] Taguchi R, Ishikawa M. Precise and global identification of phospholipid molecular species by an Orbitrap mass spectrometer and automated search engine Lipid Search. J Chromatogr A 2010;1217:4229-39.

[19] Scott TW, Ashes JR, Fleck E, Gulati SK. Effect of fish oil supplementation on the composition of molecular species of choline and ethanolamine glycerophospholipids in ruminant muscle. J Lipid Res 1993;34:827-35.

[20] Tanamati A, Oliveira CC, Visentainer JV, Matsushita M, de Souza NE. Comparative study of total lipids in beef using chlorinated solvent and low-toxicity solvent methods. J Am Oil Chem Soc 2005;82:393-7.

[21] Fogerty AC, Whitfield FB, Svoronos D, Ford GL. Changes in the composition of the fatty acids and aldehydes of meat lipids. Int J Food Sci Tech 1990;25:304-12.

[22] Boselli E, Pacetti D, Curzi F, Frega NG. Determination of phospholipid molecular species in pork meat by high performance liquid chromatography-tandem mass spectrometry and evaporative light scattering detection. Meat Sci 2008; 78:305-13.

[23] Valencak T, Ohrnberger S, Brugger K, Schreiner M. 19. Fatty acid composition of game meat: implications for human health and variability between free-ranging and farmed game: Food safety and security;2017,p. 265-77.

[24] Miller GJ, Field RA, Riley ML, Williams JC. Lipids in wild ruminant animals and steers. J Food Qual 1986;9:331-43.

[25] Dannenberger D, Lorenz S, Nuernberg G, Scollan N, Ender K, Nuernberg K. Analysis of Fatty Aldehyde Composition, Including 12-Methyltridecanal, in Plasmalogens from Longissimus Muscle of Concentrate- and Pasture-Fed Bulls. J Agri Food Chem 2006;54:182-8.

[26] Jeong BY, Ohshima T, Koizumi C. Changes in fatty chain compositions of lipid classes during frozen storage of the adductor muscle of giant ezo scallop (Patinopecten yessoensis). Comp Biochem Physiol Part B: Biochem Mol Biol 1999;122:415-22.

[27] van der Veen JN, Kennelly JP, Wan S, Vance JE, Vance DE, Jacobs RL. The critical role of phosphatidylcholine and phosphatidylethanolamine metabolism in health and disease. Biochim Biophys Acta (BBA) - Biomembranes 2017; 1859:1558-72.

[28] Fogerty AC, Whitfield FB, Svoronos D, Ford GL. The composition of the fatty acids and aldehydes of the ethanolamine and choline phospholipids of various meats. Int J Food Sci Tech 1991;26:363-71.

[29] Wang DY, Zhu YZ, Xu WM. Comparative study of intramuscular phospholipid molecular species in traditional Chinese duck meat products. Asian-Australas J Anim Sci 2009;22:1441-6.

[30] Thomas RH, Bernards MA, Drake EE, Guglielmo CG. Changes in the antioxidant activities of seven herb- and spice-based marinating sauces after cooking. J Food Comp Anal 2010;23:244-52.

[31] Yanishlieva NV, Marinova E, Pokorný J. Natural antioxidants from herbs and spices. Eur J Lipid Sci Tech 2006;108:776-93.

[32] Fogerty AC, Whitfield FB, Svoronos D, Ford GL. Changes in the composition of the fatty acids and aldehydes of meat lipids after heating. Int J Food Sci Tech 1990;25:304-12.

[33] Brites P, Waterham HR, Wanders RJ. Functions and biosynthesis of plasmalogens in health and disease. Biochim Biophys Acta (BBA)-Mol Cell Biol Lipids 2004;1636:219-31.

[34] Leray C, Cazenave J-P, Gachet C. Platelet phospholipids are differentially protected against oxidative degradation by plasmalogens. Lipids 2002;37:285-90.

[35] Callemien D, Jerkovic V, Rozenberg R, Collin S. Hop as an interesting source of resveratrol for brewers: optimization of the extraction and quantitative study by liquid chromatography/atmospheric pressure chemical ionization tandem mass spectrometry. J Agri Food Chem 2005;53:424-9. 
[36] Nakatani N. Phenolic antioxidants from herbs and spices. Biofactors 2000;13:141-6.

[37] Han J, Rhee K. Antioxidant properties of selected Oriental non-culinary/nutraceutical herb extracts as evaluated in raw and cooked meat. Meat Sci 2005;70:25-33.

[38] Bonoli M, Verardo V, Marconi E, Caboni MF. Antioxidant phenols in barley (Hordeum vulgare L.) flour: comparative spectrophotometric study among extraction methods of free and bound phenolic compounds. J Agri Food Chem 2004;52: 5195-200.

[39] Samaras T, Gordon M, Ames J. Antioxidant properties of malt model systems. J Agri Food Chem 2005;53:4938-45.

[40] Gorgas K, Teigler A, Komljenovic D, Just WW. The ether lipid-deficient mouse: tracking down plasmalogen functions.
Biochimi Biophys Acta (BBA)-Mol Cell Res 2006;1763: 1511-26.

[41] Stadelmann-Ingrand S, Pontcharraud R, Fauconneau B. Evidence for the reactivity of fatty aldehydes released from oxidized plasmalogens with phosphatidylethanolamine to form Schiff base adducts in rat brain homogenates. Chem Phys Lipid 2004;131:93-105.

[42] Embuscado ME. Spices and herbs: Natural sources of antioxidants - a mini review. J Func Food 2015;18:811-9.

[43] Harris WS. Nutrigenetics: omega-3 and omega- 6 fatty acids. In: Principles of nutrigenetics and nutrigenomics. Elsevier; 2020. p. 223-6. 